\title{
WestVirginiaUniversity
}

THE RESEARCH REPOSITORY @ WVU

Graduate Theses, Dissertations, and Problem Reports

2017

\section{Exploring Concentration and Duration Dependence in Hormesis}

Maren S. Prediger

Follow this and additional works at: https://researchrepository.wvu.edu/etd

\section{Recommended Citation}

Prediger, Maren S., "Exploring Concentration and Duration Dependence in Hormesis" (2017). Graduate Theses, Dissertations, and Problem Reports. 6449.

https://researchrepository.wvu.edu/etd/6449

This Thesis is protected by copyright and/or related rights. It has been brought to you by the The Research Repository @ WVU with permission from the rights-holder(s). You are free to use this Thesis in any way that is permitted by the copyright and related rights legislation that applies to your use. For other uses you must obtain permission from the rights-holder(s) directly, unless additional rights are indicated by a Creative Commons license in the record and/ or on the work itself. This Thesis has been accepted for inclusion in WVU Graduate Theses, Dissertations, and Problem Reports collection by an authorized administrator of The Research Repository @ WVU. For more information, please contact researchrepository@mail.wvu.edu. 


\title{
Exploring Concentration and Duration Dependence in Hormesis
}

\author{
Maren S. Prediger \\ Thesis submitted to the \\ Eberly College of Arts and Sciences \\ at West Virginia University \\ in partial fulfillment of the requirements \\ for the degree of \\ Master of Science \\ in \\ Analytical Chemistry \\ Jonathan Boyd, Ph.D., Committee Chair \\ Suzanne Bell, Ph.D. \\ Peng Li, Ph.D. \\ C. Eugene Bennett Department of Chemistry \\ Morgantown, West Virginia \\ 2017
}

Keywords: Hormesis, Phytochemicals, Resveratrol, Energy Metabolism, Duration Dependence, Cell Signaling Copyright 2017 Maren S. Prediger 


\section{ABSTRACT \\ Exploring Concentration and Duration Dependence in Hormesis}

Maren S. Prediger

The phenomenon of hormesis, characterized by beneficial low-exposure stress-protective effects, has experienced increasing interest by the scientific community. Elucidating the underlying cellular signaling pathways that lead to a new homeostatic state can provide crucial information about new therapeutic targets to prevent and treat diseases. Commonly investigated for hormetic behavior are plant-based substances (phytochemicals), such as quercetin, epigallocatechin gallate, curcumin, and resveratrol. The polyphenol resveratrol, found in peanuts, grapes, and subsequently in wine, is known for a variety of effects - beneficial and detrimental - depending on the investigated cell type and concentration. In HepG2 cells, an increase in proliferation has been observed previously at doses between $10 \mu \mathrm{M}$ to $100 \mu \mathrm{M}$ after 16 hours, while higher doses decreased cell viability markedly, eventually leading to cell death. For other compounds, literature searches provide conflicting data on the hormetic capabilities and subsequently on the associated concentrations. This work aims to clarify the concentration and exposure duration dependence in hormesis. The four aforementioned compounds were screened for their hormetic behavior in a human liver cancer model by assessing the effects of varying concentrations on metabolic activity and plasma membrane integrity. Quercetin, epigallocatechin gallate, and curcumin did not show hormetic properties in the investigated concentration range during a 24-hour exposure. Resveratrol qualified for further experiments where cells were subjected to 0.1 to $500 \mu \mathrm{M}$ for six, twelve, 24 , 48, and 72 hours. A significant change in metabolic activity at concentrations of 50, 100, and $250 \mu \mathrm{M}$ was found between twelve and 24 hours, as well as a significant increase in plasma membrane degradation after 24 hours at doses higher than $100 \mu \mathrm{M}$. This demonstrates a noticeable change in cellular behavior between the twelve- and 24-hour mark, associated with resveratrol concentrations from 50 to $250 \mu \mathrm{M}$. Future research should include real-time assessment of energy markers, preferably up to 24 hours, to pinpoint timepoints of metabolic switches, and subsequently study the changes that underlie hormesis at these timepoints. 



\section{DEDICATION}

This thesis is dedicated to Katharina Brylla, an extraordinary women, mother, and grandmother. She persisted through unimaginable adversities in the darkest times of European history without losing herself. Not everyone can live a happy and productive life after these experiences and enjoy the small things in life, including advocaat and "Mensch Ärgere Dich Nicht". She was the inspiration for long days and short nights in the hope of spending a few more joyful moments in her presence after graduation. Unfortunately, I was too late. 


\section{ACKNOWLEDGEMENTS}

Firstly, I thank Dr. Jonathan Boyd for his advisory patience over the past two and a half years. Our shared work has taught me a great deal about myself, science, life, the importance of integrity, and the nature of academia. I am grateful for the many opportunities.

I would also like to thank my committee members, Dr. Suzanne Bell, and Dr. Peng Li, as well as former committee members, Dr. Brian Popp, Dr. Carsten Milsmann, and Dr. Matthew Loos, for their continuous support, advice, and encouragement throughout my graduate years. Additionally, I would like to express my appreciation for everything Inga Richter and Alexander Maxones have helped me with during my exchange in Fulda (Germany), especially for the perspective I have gained throughout numerous valuable conversations on what really matters in life.

A special "thank you" goes to my lab group members, Dr. Julie Vrana, Alice Han, Nicole Prince, and Julia Mouch. You girls made the office and the department a warm and homey place, even late at night or very early in the morning, and filled much and sometimes not so much needed brain-breaks with laughter, coffee, peanut M\&Ms, and all the fine departmental gossip. I'll be sad to leave behind the game nights, puppy dates, and all the other small shindigs that made graduate life bearable.

Rob Crovak, thank you for being a great friend and roommate, reminding me that it is ok to take a Sunday afternoon off, and listening to my German radio alarm every single morning without a single complaint. You make the best dips and banana-chocolate bread in the world, and if plan A does not work out, I would definitely invest in your plan B.

To my WVU rifle family, I am blessed to have and have had all of you in my life. Especially Dr. Lindsay Hammond and Coach Jonathan Hammond, who have always had an open door and open ear for me, even after graduating from the team. Your family is an inspiration and I could have not asked for better athletic counseling (and life counseling over salmon skin rolls). I want to specifically recognize two rifle ladies, Petra Zublasing and Živa Dvoršak, for their unconditional 
friendship, as well as Justin Pentz, who never fails to make time when handyman expertise is needed. All of you had an unimaginable impact on my life.

Last, but not least, I owe my deepest gratitude to my parents and my sister, who have always helped me talk my way through issues to arrive at the right decision, and never hesitated to ship over the smallest and silliest German products because they knew it would be honey for my soul. I cannot thank them enough for having my back and handling tedious administrative issues back home, so that I would not have to worry about them. 


\section{TABLE OF CONTENTS}

$\begin{array}{lr}\text { Abstract } & \text { ii } \\ \text { Dedication } & \text { iii } \\ \text { Acknowledgements } & \text { v } \\ \text { Table of Contents } & \text { vii } \\ \text { List of Figures } & \text { ix } \\ \text { List of Tables } & \text { xi } \\ \text { List } \text { of Abbreviations } & \text { xiii }\end{array}$

1. Introduction: Aspects of Cellular Signaling, Energy Demand, and Hormesis 1

1.1. Cellular Signaling: Function and Cellular Constituents Involved 2

1.1.1. Membranes 3

1.1.2. Signaling in the Mitochondria 3

1.1.3. Temporal and Spatial Aspects of Signaling 4

1.2. Cellular Energy Requirement, Storage, and Metabolism 5

1.2.1. Redox Coenzymes: Nicotinamides and Flavins 6

1.2.2. ATP 7

1.2.3. Metabolic Reprogramming in Cancer Cells 8

1.2.4. Nutrient and Energy Sensing 9

1.3. Apoptosis and Autophagy 11

1.3.1. Apoptosis 11

$\begin{array}{ll}\text { 1.3.2. Autophagy } & 12\end{array}$

1.4. Hormesis and Hormetic Compounds $\quad 13$

1.4.1. Quercetin 14

1.4.2. Epigallocatechin Gallate 15

1.4.3. Curcumin 15

$\begin{array}{ll}\text { 1.4.4. Resveratrol } & 16\end{array}$

2. Experimental Design, Methods, and Materials 17

2.1. Experimental Design 17

2.1.1. In vitro Model 17 
2.1.2. Cell-based Assays 17

2.2. Methods and Materials 19

2.2.1. Materials 19

2.2.2. Cell Culture 20

2.2.3. Dosing 20

2.2.4. Assays 21

2.2.4.1. MTT Assay 21

2.2.4.2. Plasma Membrane Degradation Assay 21

2.2.5. Data Evaluation and Statistical Analysis 22

3. Results and Conclusion $\quad 23$

3.1. Substance Screening 23

3.1.1. Quercetin, Epigallocatechin Gallate, and Curcumin 23

3.1.2. Resveratrol 26

3.2. Resveratrol: Concentration and Duration Dependence 27

3.3. Conclusion 33

4. Future Directions

4.1. Assigning Crucial Energetic Signaling Timepoints 35

4.2. Resolve Metabolic Switches in Cellular Metabolism 37

Appendix A - Hormetic Behavior of Sulforaphane 39

Appendix B - Impact of Cell Population and Instrumentation 43

$\begin{array}{ll}\text { Bibliography } & 47\end{array}$ 


\section{LIST OF FIGURES}

Figure 1 Stylized curves illustrating a dose-response curve that shows hormetic behavior.

Figure 2 Overview of the converging pathways in carbohydrate, peptide, and lipid metabolism.

Figure 3 Overview of the electron transport chain and ATP synthase.

Figure 4 Chemical structures of curcumin, resveratrol, quercetin, and epigallocatechin-3-gallate.

Figure 5 Metabolic activity and plasma membrane degradation after 24-hour exposure to epigallocatechin gallate, resveratrol, quercetin, and curcumin.

Figure 6 Metabolic activity and plasma membrane degradation after exposure of HepG2 cells to resveratrol for $6,12,24,48$, and 72 hours.

Figure 7 Metabolic activity of HepG2 cells exposed to resveratrol for 6 to 72 hours.

Figure 8 Plasma membrane degradation of HepG2 cells exposed to resveratrol for 6 to 72 hours.

Figure A-1 Chemical Structure: Sulforaphane

Figure A-2 Metabolic activity after 24-hour exposure to sulforaphane.

Figure B-1 Comparison of metabolic activity data after exposure of HepG2 cells to epigallocatechin gallate, quercetin, and resveratrol from two different laboratories with varying cell population, instrumentation, and assay reagents. 


\section{LIST OF TABLES}

Table 1 Summary of statistically significant changes in metabolic activity and plasma membrane integrity by compound concentration compared to untreated vehicle controls and the previous concentration.

Table 2 Summary of statistically significant changes in metabolic activity and plasma membrane integrity between exposure times by resveratrol concentration.

Table 3 Summary of statistically significant changes in metabolic activity and plasma membrane integrity after varying exposure times by resveratrol concentration compared to untreated vehicle controls or the previous concentration

Table A-1 Summary of statistically significant changes in metabolic activity by sulforaphane concentration compared to untreated vehicle controls and previous concentrations.

Table B-1 Comparative summary of statistically significant changes in metabolic activity by compound concentration compared to untreated vehicle controls and previous concentrations. 


\section{LIST OF ABBREVIATIONS}

ADP adenosine diphosphate

AMP adenosine monophosphate

AMPK adenosine monophosphate-activated protein kinase

Atg autophagy-related

ATP adenosine triphosphate

CDR cell danger response

DISC death-inducing signaling complex

DMEM Dulbecco's Modified Eagle's Medium

DMSO dimethylsulfoxide

EDTA ethylenediaminetetraacetic acid

ETC electron transport chain

FAD $^{+} \quad$ flavin adenine dinucleotide

FADH2 $_{2}$ reduced flavin adenine dinucleotide

FBS fetal bovine serum

GCK glucokinase

GCN2 general control nonderepressible 2 protein

GLUT2 glucose transporter 2

GPCR G-protein coupled receptor

hOGG1 8-oxyguanine DNA glycosylate

MT metallothioneins

mTOR mammalian/mechanistic target of rapamycin

mTORC1 mammalian/mechanistic target of rapamycin complex 1

MTT 3,[4,5-dimethylthiazol-2-yl]-2,5-diphenyl-tetrazolium bromide

NAD $^{+} \quad$ nicotinamide adeninde dinucleotide

NADH reduced nicotinamide adenine dinucleotide

NADP $^{+} \quad$ nicotinamide adeninde dinucleotide phosphate 


$\begin{array}{ll}\text { NADPH } & \text { reduced nicotinamide adenine dinucleotide phosphate } \\ \text { Nrf2 } & \text { nuclear factor (erythroid-derived 2)-like 2 } \\ \text { PBS } & \text { phosphate buffered saline } \\ \text { PCD } & \text { programmed cell death } \\ \text { RAPTOR } & \text { regulatory-associated protein of mTOR } \\ \text { ROS } & \text { reactive oxygen species } \\ \text { SIRT1 } & \text { NAD-dependent deacetylase sirtuin-1 } \\ \text { TNF } & \text { tumor necrosis factor } \\ \text { tRNA } & \text { transfer RNA (ribonucleic acid) } \\ \text { TSC2 } & \text { tuberous sclerosis complex 2 } \\ \text { ULK1 } & \text { UNC-51 like kinase 1 }\end{array}$




\section{Introduction: Aspects of Cellular Signaling, Energy Demand, and Hormesis}

Multicellular organisms are in a constant fight of survival with the environment and everything stands in exchange of matter and energy. It is a battle on two fronts: the physical environment, which includes insults from sunlight, dryness, wind, storm, or cold, and the chemical environment, represented by myriads of harmful and/or beneficial micro- and macromolecules. ${ }^{1,2}$ Every living species on this planet, at any given moment in history up until now, has evolved and adapted to the direct environment, in an effort to maximize the likelihood of survival and procreation. Adaptions can be long lasting changes in the genetic sequence, or in its expression, that affect subsequent generations, but often are transient changes to handle immediate exposures. On the molecular and cellular level, this can be achieved by settling for a state of equilibrium, that is different than the state before, particularly in hormesis.

The phenomenon of hormesis is commonly described as a biphasic dose-response behavior, where low doses of a compound exert a beneficial effect on cells or tissue, while higher doses prove detrimental. ${ }^{3-6}$ More broadly, it can also be stated with the familiar saying: "what does not kill you, makes you stronger". Rigorous exercise and simultaneous energy restriction have long been seen as the original trigger for hormesis, based on a switch between "stress resistance mode" and "growth/plasticity mode". Short periods of ischemia also appear to "precondition" the heart for a

more severe ischemic event. ${ }^{7}$ However, the principle of hormesis has already been described in the late $19^{\text {th }}$ century by Prof. Hugo Schulz, when he observed stimulation of bacterial metabolism through bactericidal agents at low doses. ${ }^{8}$ The underlying concept of small amounts of injury strengthening the system in the long run has been attributed to the effects on receptor signaling, signaling pathways such as the mammalian (mechanistic) Target of Rapamycin, and cellular antioxidant systems. ${ }^{4,8,9}$ Theories on how constant low-level stress can be beneficial include two aspects: an increase in repair behavior, and an adaption towards a more stress-resistant state within the cell. In the early years of hormesis research, studies focused on toxic substances, including metals, but the scope of a "mild stressor" has been broadened to include environmental stimuli as well, especially plant-based substances. ${ }^{4,7}$ Generally, a hormetic effect is attributed to a stressor, may it be of physical, nutritional, or environmental origin, when the dose-response assessment has 
biphasic character (inverted U- or J-/U- shaped curves). ${ }^{10,11}$ These curves display a hormetic zone, where the associated dose stimulates the assay response up to $30-60 \%$ of the control (significantly, especially with respect to the physiological consequences). ${ }^{8,10}$ Figure 1 shows exemplary curves if one were to measure cell viability and cell death in a dose-dependent manner: The hormetic zone is then defined as the area where a decrease in cell death to a percentage less than the control value or an increase in cell viability above control values is observed.
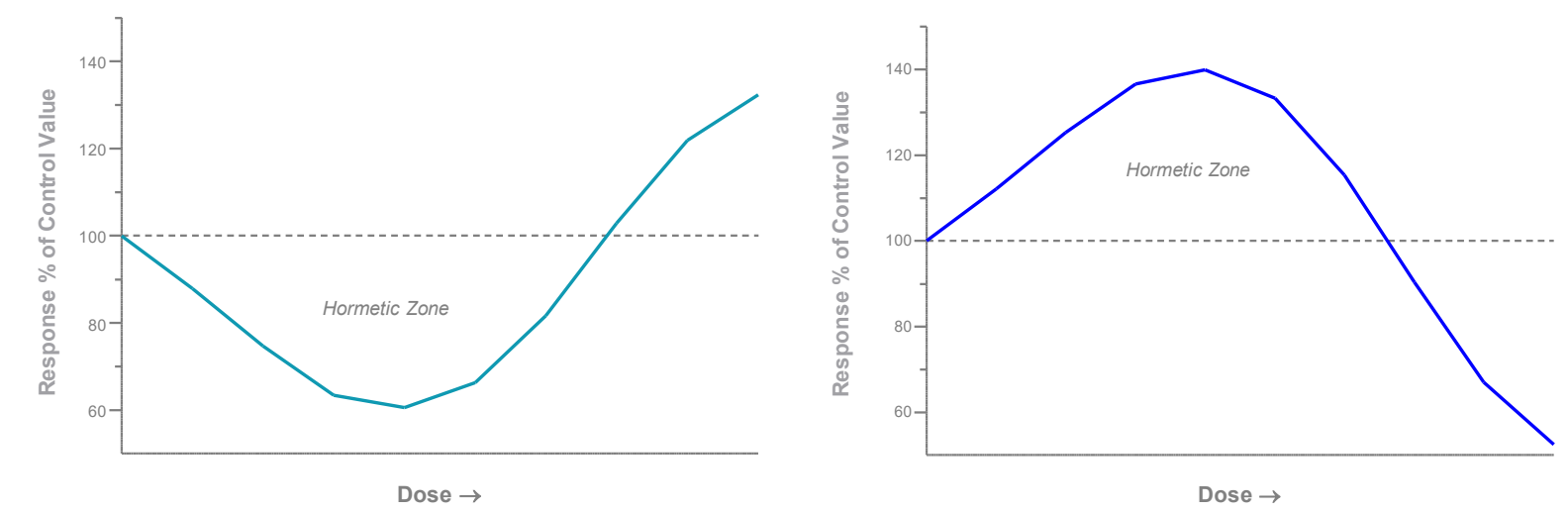

Figure 1| Stylized curves illustrating a dose-response curve that shows hormetic behavior.

On the left, a U-shaped curve as it would ideally be found when measuring cell death, for example. On the right, an inverted U-shaped curve, as it would ideally be found when measuring cell viability, for example.

To assess, understand, take advantage of, or undo a compound's effect on a system, it is necessary to characterize the cellular signaling associated with the molecule. While it is important to know how the molecule distributes throughout the system, e. g. where it is absorbed, stored, or metabolized, it is even more important to detect the changes the molecule and its metabolites evoke in the systems smallest unit, the cell, and the associated time course. ${ }^{12}$

\subsection{Cellular Signaling: Function and Cellular Constituents Involved}

A xenobiotic insult generates a variety of responses inside a cell, a whole machinery of different mechanisms that deal with the foreign substance and its metabolites. A lot of these mechanisms are evolutionary conserved and the entirety of the responses are termed the cell danger response (CDR). ${ }^{2}$ For the machinery to deal with the xenobiotic successfully, all incorporated pathways 
need to communicate with each other across cellular compartments and membranes in signal transduction.

\subsubsection{Membranes}

Lipophilic in nature, the cell membrane core establishes a very effective barrier between the extracellular environment and the cytosol as well as between the cytosol and organelle matrices. Only select molecules can diffuse freely through the semipermeable membranes, based on their size and hydrophobicity. Passive diffusion through the membrane is possible for uncharged, lipophilic molecules that "dissolve" in the membrane (e.g. steroid hormones derived from

cholesterol). ${ }^{13}$ Polar molecules and ions, except water, cannot freely cross the membrane due to their lipophobic character. Many chemical species, such as metabolic products from carbohydrate and protein metabolism, as well as electrolytes, and growth factors, must transfer in and out of cells. Not every molecule needs to enter the cell, to communicate the environmental status quo. Eukaryotic cells are well-equipped to sense signals outside of the cell, amplify them inside the cell, and initiate an appropriate response. Membrane spanning sensor proteins, or receptor proteins, which are present on cell and organelle membranes, are capable of binding a ligand on one side (e.g. extracellular) and activating secondary messengers on the other side (e.g. in the cytosol). ${ }^{14}$ They thereby propagate the signal into the cell. In return, the cell can signal its status quo to the surrounding environment through lipid vesicles and exosomes, for example.

\subsubsection{Signaling in the Mitochondria}

The mitochondria has been recognized as a highly important organelle in cell signaling as it is actively involved in apoptosis, autophagy, immune responses, and calcium signaling. ${ }^{15}$ These functions are intimately interwoven: cell death in the form of apoptosis is considered the first-line of defense against incoming pathogenic threats. At the same time, cell death initiates an immune response to clear the pathogenic threat, which can be controlled through autophagy as a prosurvival mechanism. ${ }^{15}$ The mitochondria is, at the same time, considered the "powerhouse" of the cell, due to its role in energy production in the form of adenosine triphosphate (ATP). 
As a side-effect of energy production in the mitochondria, reactive oxygen species (ROS) are produced due to electrons leaking from the electron transport chain. Despite the overall harmful effects of ROS on cellular molecules, recent research suggests a beneficial impact from low concentrations of ROS. It is thought that these concentrations may stress the cell just enough to cause adaption and prolong longevity instead of cell death, ${ }^{16}$ which might even decrease the pace of aging. Ji et al. (2010), Sauer et al. (2001), and Linley et al. (2012) connect an increase in hydrogen peroxide from immediate ROS detoxification, and ROS in general, to the enhanced regulation of embryonic stem cell differentiation, intracellular cell growth, and neurokinin signaling in sensory neurons, respectively. ${ }^{17-19}$

\subsubsection{Temporal and Spatial Aspects of Signaling}

A cell is prepared to respond to signals in various places, and the duration and ramification of the signal vary significantly based on the nature of the stimulant. The duration of a signal depends on the pathways involved, and cellular compartmentalization offers distinct locations for distinct functions. Reaction kinetics and substrate availability also dictate the temporal aspect of signaling, since some reactions take longer than others. ${ }^{12,20}$ Not every process occurs everywhere in the cell; organelles have a specific microenvironment that increases the likelihood of certain reactions more over others. The early pictures of linear signal pathways made way for complex signaling cascades and networks, that can be highly conserved, such as signaling through cell cycle checkpoints, or can be highly complex and even vary for the same signal molecule depending on the tissue type.

The basis of spatially distributed signals and reactions is a difference in diffusivity for active/inactive forms of signaling molecules. While it is known that the activity of an enzyme changes with posttranslational modification, the diffusivity also changes, creating separate concentration gradients for the two forms of the same molecule. Additionally, due to slightly changed physical properties, the preference in microenvironment can change, and therefore the localization within the cell. ${ }^{21}$ For example, when a ligand binds to a G-protein coupled receptor (GPCR) on the membrane surface, a kinase causes a secondary response right inside the membrane. Through the secondary response molecule, another kinase more distant from the membrane is activated, and so on and so forth. Signals are eventually terminated by phosphatases in the cytosol, but not without branching into and initiating more signaling. ${ }^{20}$ The exact location 
of termination, closer or not so close to the membrane, depends on the strength (concentration) of the original GPCR signal. The stronger the signal, the longer the transmission range inside the cytosol and the more diverse pathways can theoretically be activated. This also ties into the temporal aspect of signaling, since it will not take as long to activate a pathway close to the membrane as it does when it is initiated somewhere in the cytosol, spatially further away from the original signal. Another example is the initiation of apoptosis, where several pathways at several locations (receptors, mitochondria, endoplasmic reticulum, etc.) can initiate a cascade of signals that eventually seem to converge at the mitochondria and then start the cleavage of procaspases inside the cytosol. ${ }^{22}$

\subsection{Cellular Energy Requirement, Storage, and Metabolism}

Cellular signaling is especially important to communicate the metabolic state of a cell within the cell and to the environment. Intermediates in metabolic pathways are therefore also considered signaling molecules and can import information. Metabolic processes are either of anabolic nature, to build larger biomolecules from smaller parts, or of catabolic nature, to break down larger biomolecules into smaller parts. ${ }^{23,24}$ Catabolic pathways release energy during their breakdown reactions, while anabolic pathways require energy input in the biosynthesis of macromolecules. The energy that was released or needed in these pathways is stored in highly energetic covalent bonds such as phosphate esters and phosphoanhydride bonds found in ATP or nicotinamide adenine dinucleotide phosphate (NADPH). ${ }^{23,25-27}$ Coupling of anabolic and catabolic processes connects energy-requiring and energy-releasing reactions, which creates interrelated networks that overall yield an increase in entropy.

In eukaryotic cells, several catabolic pathways cross, interact, feed into each other, and can eventually all lead to the production of energetic resources (Figure 2). ${ }^{26}$ Detailed descriptions of the metabolism of the three main macronutrients (carbohydrates, proteins, and lipids) can be found in literature. ${ }^{23,25,27}$ Briefly, lipids are oxidized in a step-wise fashion via $\beta$-oxidation, yielding acetyl-CoA, NADH and flavin adenine dinucleotide $\left(\mathrm{FADH}_{2}\right)$, while carbohydrates - once broken down into single glucose molecules - are metabolized in several pathways depending on the availability of oxygen. The first part of glycolysis is universal, oxygen independent, and produces two equivalents of pyruvate, ATP, and NADH. Anaerobic conditions lead to the fermentation of pyruvate into lactate (oxidative process). Aerobic conditions lead to three consecutive pathways 
in the mitochondria. First, pyruvate is oxidized into acetyl-CoA while creating an equivalent of NADH, then acetyl-CoA feeds into the citric acid cycle that yields three molecules of NADH and one molecule of $\mathrm{FADH}_{2}$ per acetyl-CoA. Lastly, the energetic coenzymes participate in oxidative phosphorylation in the electron transport chain to produce ATP directly. Proteins are primarily broken down into their respective single amino acids, which are subsequently used for the synthesis of peptides, but in times of energy demand they can feed into cellular respiration and therefore can also serve as an energy resource. ${ }^{24}$

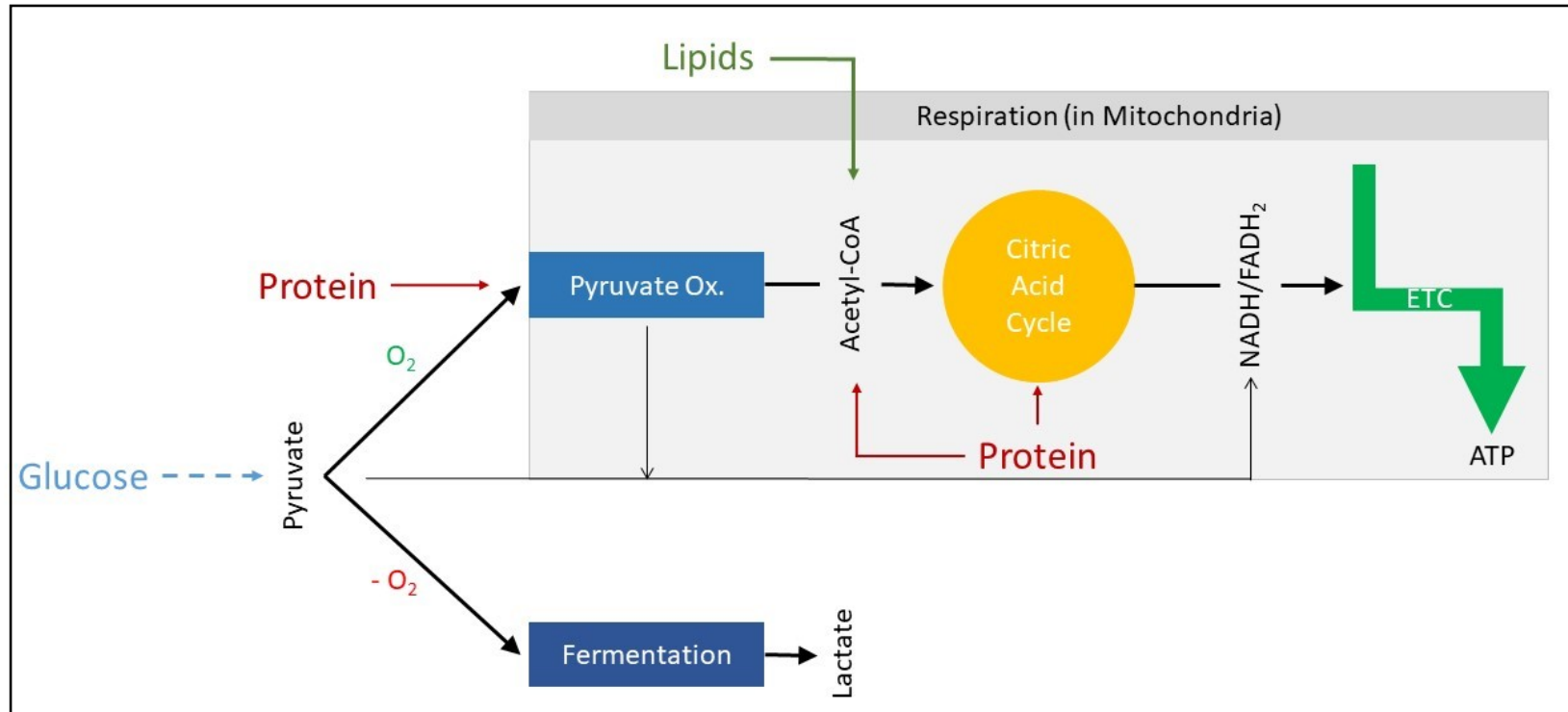

Figure 2| Overview of the converging pathways in carbohydrate, peptide, and lipid metabolism.

\subsubsection{Redox Coenzymes: Nicotinamides and Flavins}

Oxidation and reduction reactions are often catalyzed by enzymes that depend on redox coenzymes, ${ }^{28}$ which transiently store released energy, mostly in the form of one or two electrons. $^{29,30}$ Two coenzymes families are important regarding energy metabolism: $\mathrm{NAD}^{+}$ (nicotinamide adenine dinucleotide) and flavins. The former is the precursor for $\mathrm{NADP}^{+}$ (nicotinamide adenine dinucleotide phosphate). ${ }^{31}$ Both are highly involved in cellular metabolism as hydride-transfer enzymes, since they can take up two electrons and a proton to form their reduced counterparts NADH and NADPH. ${ }^{31}$ The dephosphorylated form is of special interest in this regard because it can efficiently cause the translocation of a proton at the inner mitochondrial 
membrane to establish the proton gradient that is the driving force for ATP production in oxidative phosphorylation. Flavin adenine dinucleotide (FAD) on the other hand is capable of one and two electron transitions, either sequentially or simultaneously. ${ }^{23}$ In the electron transport chain (ETC), unpaired electrons from oxidized metabolites can be transferred to diatomic oxygen through $\mathrm{FADH}_{2}($ Figure 3$){ }^{27}$

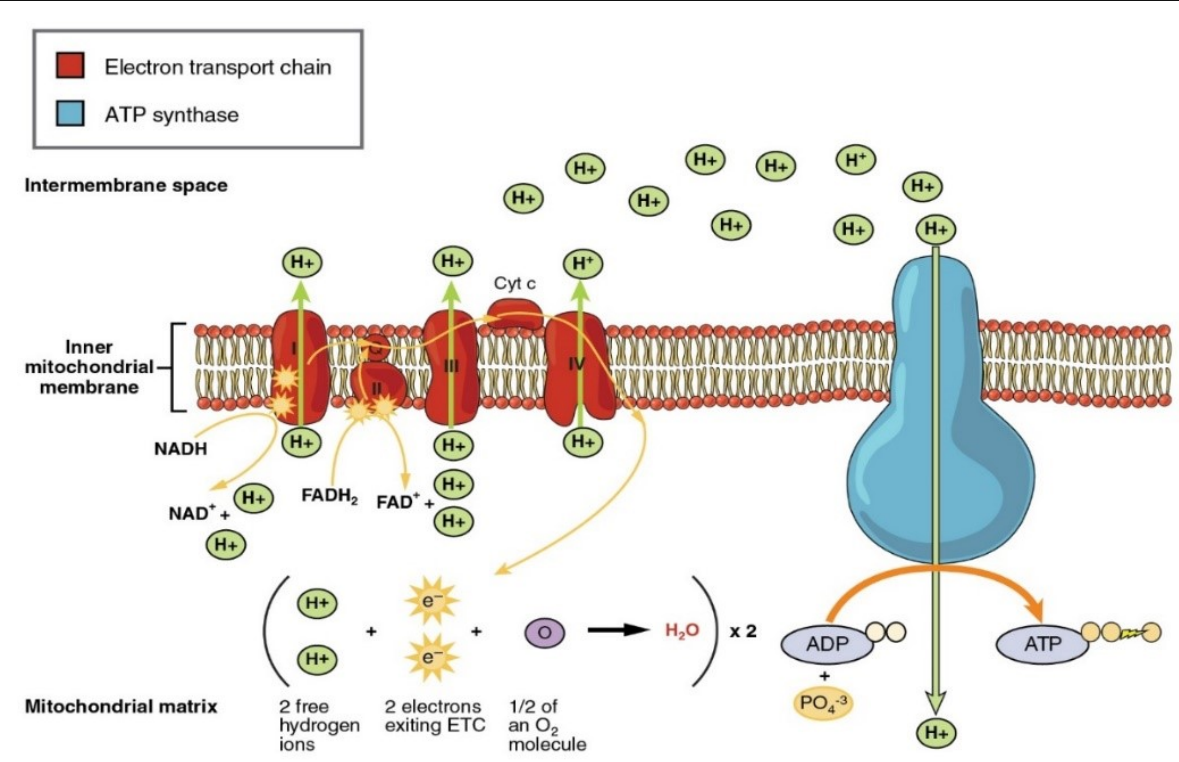

Figure 3| Overview of the electron transport chain and ATP synthase.

The schematic depicts the membrane-bound complexes I through IV and ATP synthase and their action in oxidative phosphorylation: Complex I, III, and IV establish a proton gradient, while Complex II facilitates an electron exchange that ultimately leads to the formation of water. ATP synthase phosphorylates ADP through the motive force from the proton gradient.

Figure reprinted from: Figure 5, OpenStax. Carbohydrate Metabolism (OpenStax CNX, 2015). Download for free at http://cnx.org/contents/9d68abf9-4c2e-4ef7-88d1-c963c5c844b9@4.

\subsection{2. $A T P$}

ATP is considered the energy currency of the biological metabolism. ${ }^{32}$ As Voet and Voet (2011) state it:

"the cellular role of ATP is that of a free energy transmitter rather than a free energy reservoir." 23 
The key to its function lies in the three phosphate groups and the two covalent bonds between them, that hold high potential energy. The first phosphate group attached to the nucleoside is bound through a phosphate ester bond to the 5' oxygen on the nucleoside's ribose. The additional two phosphate groups then form phosphoanhydride bonds to each other $(\alpha, \beta-$ and $\beta, \gamma-$ linkages $){ }^{27}$ The hydrolysis of one mol of ATP to adenosine diphosphate (ADP) has been calculated to release $7.3 \mathrm{kcal} / \mathrm{mol}$ under standard condition and $14 \mathrm{kcal} / \mathrm{mol}$ under cellular conditions $(30.5 \mathrm{~kJ} / \mathrm{mol}$ and $57 \mathrm{~kJ} / \mathrm{mol}$, respectively). ${ }^{23-25,27}$ Eukaryotic ATP is directly produced via two pathways: Firstly, through oxidative phosphorylation in the mitochondria, where the membrane proteins of the electron transport chain use the energy from electron carriers to establish a proton gradient in the mitochondrial intermembrane space and couple protons to oxygen to form water (Figure 3 ). The relief of the proton gradient through the peptide ATP synthase yields the sought-after energy-rich nucleotide. The second pathways is glycolysis in the cytosol, which also releases ATP, but in smaller quantities (two molecules per glucose). ${ }^{33}$ Other catabolic pathways indirectly lead to the production of energetic adenosine as well, either by providing glucose, intermediates for the citric acid cycle, or reduced electron carriers. The breakdown of ATP, to adenosine diphosphate and adenosine monophosphate, fuels cellular processes that would otherwise be energetically unfavorable. Additionally, some sources see ATP, ADP, and AMP as a stimulated extracellular signaling molecule and neurotransmitter in purinergic signaling associated with the cell danger response, especially in neuronal cells. Increased secreted ATP from stressed cells then inevitably evokes an immune response. ${ }^{2}$

\subsubsection{Metabolic Reprogramming in Cancer Cells}

While most cells rely heavily on mitochondrial oxidative phosphorylation to produce ATP, it was observed by Otto Warburg et al. at the beginning of the past century, that carcinoma cells turn over glucose into lactose $125 \mathrm{x}$ more than blood, up to 200x more than an inactive frog leg muscle, and $8 \mathrm{x}$ more than an active frog leg muscle at its maximum capacity under anaerobic conditions; this trend does not change significantly (as it should) under aerobic conditions. ${ }^{34}$ The overall findings were, that cancer cells show a higher glycolytic flux via fermentation, even if oxygen is available. This has since been termed the "Warburg Effect". ${ }^{35}$ The exact benefits of the altered metabolism

for a cancer cell are not fully understood yet, ${ }^{5}$ but several theories have been proposed, including: 
1) glycolysis and subsequent fermentation is a faster way to produce ATP when resources are low, which gives tumor cells an evolutionary advantage over the surrounding tissues; 2) the flux through glycolysis and lactate formation provides more precursors for biomass production and therefore aids in rapid proliferation; ${ }^{36} 3$ ) the reprogrammed metabolism is not a hallmark of cancer cells, but the source of cancer development itself. No matter which theory is true, the difference in energy production needs to be addressed if one is to study energetic markers in a cancer cell model such as the herein used HepG2 cell line.

\subsubsection{Nutrient and Energy Sensing}

Cellular processes are tightly regulated at all levels, and every process has a certain energy requirement. Cells manage to maintain their status, through mechanisms that sense the energy requirement and relate it to nutrient capacity and energy availability. In case of an imbalance, metabolic pathways can then be stimulated as needed. How effective an organism can sense fluctuations in environmental nutrient levels determines evolutionary selectivity. ${ }^{37}$ Two processes need to be considered for nutrient sensing: a nutrient binding to its receptor, which can propagate the information of binding, and the ability to detect and sense levels of a compound that directly reflect nutrient concentration. ${ }^{37}$ Sensing mechanisms vary for the main three macronutrients, and vary for intra- and extracellular detection.

When amino acids are scarce, empty tRNAs (the molecules that shuttle amino acids to ribosomes for peptide synthesis) can be detected intracellularly by the general control nonderepressible 2 protein (GCN2), which can inhibit translation. Lipids, especially fatty acids, bind to G-protein coupled receptors and set off the release of hormones and other messenger molecules. ${ }^{37}$ Glucose sensing has a very complex regulatory framework, due to its importance as the main energy source in mammalian systems. A multitude of mechanisms exist to assess glucose levels inside and outside of a cell. One of them is the activity of glucokinase (GCK), which is only active in a state of intracellular glucose abundance and therefore has the capacity to signal glucose levels. For extracellular levels, the glucose transporter GLUT2 can import glucose into the cell when the concentration is high, but exports out of the cell when levels are lower than the intracellular concentration. AMP-activated protein kinase (AMPK) and mTOR are universally seen as sensors of cellular energy and nutrient status in eukaryotic cells. ${ }^{38,39}$ AMPK is sensitive to the ratio of 
AMP:ATP and influences catabolic and anabolic processes to both, reduce or increase, ATP production or expenditure. ${ }^{38,40}$ Phosphorylation of the kinase also modulates its activity to an increase of more than 100-fold compared to the unphosphorylated form. On top of that, influx of calcium ions into the cytosol increases AMPK activity and triggers production of ATP. ${ }^{41}$ Extensive reviews on the activation and signaling involvement of AMPK have been published by Hardie. ${ }^{41-45}$ Similarly to AMPK, mTOR has been suggested as a direct sensor of intracellular ATP as its activity decreases with the levels of the nucleotide. ${ }^{39}$ Amino acids, fatty acids, metabolites from nutrient catabolism reactions, and some of their enzymes also alter its activity; ${ }^{39}$ therefore, mTOR additionally qualifies as a nutrient sensor. Since both, AMPK and mTOR are highly involved in nutrient and energy sensing, it is no surprise that their pathways cross and affect each other's targets and activities. Their signaling reach is not confined to nutrients and energetics though, both molecules have critical impact on other functional domains, including cytoskeletal dynamics, cell growth, and programmed cell death. ${ }^{46}$ Additionally, signaling around mTOR and AMPK are essential for the intracellular communication of nutrient levels regarding all three macronutrient classes. ${ }^{37}$

A step removed from nutrient awareness is the capability to use these nutrients to produce energy, or to decide to store them if enough energy is available at a given moment. However, that requires the systems to be able to sense energy demand and energy availability, especially in terms of ATP, if a system wants to remain within acceptable metabolic boundaries. A relatively large fraction, almost $30 \%$, of cellular ATP is devoted to ion pumps, which maintain ion homeostasis under normal conditions. However, it has been shown that under anoxia, the fraction increases to $74 \%$ and expenditure on other processes decreases, suggesting a hierarchical allocation of energy resources to the most important activities. ATP itself can act as a regulator for certain pathways, for example: high concentrations of ATP inhibit phosphofructokinase, the first enzyme in glycolysis, which reduces the production of ATP. Rising levels of AMP on the other hand, a sign of an increase of ATP hydrolysis from energy-requiring reactions, activate the same enzyme, which increases the rate of glycolysis and leads to an increase in ATP production through oxidative phosphorylation. The same is true for AMPK, which decreases in activity with rising levels of ATP. $^{47}$ 


\subsection{Apoptosis and Autophagy}

Eukaryotic organisms are made up of many cells, each with checks and balances to ensure energy supply, upkeep of function, and proliferation. However, most cells have a limited lifespan which is tightly regulated by programmed cell death (PCD) pathways. They ideally regulate a cell's downfall intracellularly to go by in an orderly fashion without dragging the immediate environment down the same path. Two primary forms of these PCDs have been identified based on distinctly different morphological features ${ }^{48}$ : apoptosis (type I) and autophagy (type II). Anoikis is also categorized as a PCD, however, this form of cell death occurs only when a cell detaches from the surrounding tissue and undergoes a process very similar to apoptosis due to the loss of connectivity. ${ }^{49}$

\subsubsection{Apoptosis}

Apoptosis is the main form of programmed and genetically encoded cell death, that is especially important in early stages of mammalian development, where organs and extremities form, that would otherwise be shapeless. ${ }^{50}$ Balanced cell proliferation and cell death upholds the status quo in a biological system. Irregular apoptosis has been connected to a plethora of diseases, the most prominent being cancer, where the apoptotic programs are turned off or inhibited. Morphological changes that are characteristic for apoptosis, and easily studied under a microscope, include the condensation of chromatin and a shrunken nucleus, formation of blebs and apoptotic bodies, and degraded plasma membranes. ${ }^{49-51}$

Initiation can either be extrinsic, intrinsic, or granzyme related. ${ }^{48,51-53}$ If an extracellular molecule from the TNF family (tumor necrosis factor) binds to their so called "death" receptors on the plasma membrane, a death-inducing signaling complex (DISC) is formed, and inactive procaspases (caspase 8 or 10) can dimerize and activate each other by cleavage into caspases. ${ }^{49,54}$ Intrinsic apoptosis can be triggered in nuclear, reticular, lysosomal, and plasma-membrane pathways, ${ }^{22}$ which all seem to converge at the point of Bax/Bak pore formation at the mitochondrial membrane. Bax and Bak proteins belong to a subfamily of pro-apoptotic molecules in the family of Bcl-2, which play an integral part in apoptosis. ${ }^{51}$ Depending on the number of Bcl2 homology domains, members of different subfamilies can have quite the opposite effect on 
mitochondrial membrane integrity. Bcl-2 for example inhibits Bax and Bak interaction by binding to them. ${ }^{48,49,51,55}$ In the case of Bax and Bak interaction, insertion into the mitochondrial membrane leads to pore-like channel formation. With the formation of these pores on the outer mitochondrial membrane, the permeability increases drastically. ${ }^{53}$ Thus, species such as cytochrome $\mathrm{c}$ are released into the cytosol. ${ }^{52}$ Once in the cytosol, cytochrome c activates caspases (caspase 9), which ultimately lead to cell death. ${ }^{51}$ Caspases are the best option, if one wants to study a compounds effect on apoptosis, although it is important to distinguish between the initiating caspases $(2,8,9$, $10)$ and the effecting caspases $(3,6,7)$, since their activity depends on the timing in the program of apoptosis. $^{48}$

\subsubsection{Autophagy}

The term autophagy very literally describes a biochemical processes, where, in accordance with the word's origin, a cell digests itself. When nutrients are less abundant, cellular constituents can be broken down to yield resources for energy production until nutrients are available again. ${ }^{56,57}$ Several factors indicate that the recycling capacity in autophagy is an important part of homeostatic control and experiments showed a dependence on autophagy for cell survival. ${ }^{58}$ However, autophagy can also lead to cell death. ${ }^{53,55,56}$ During autophagy, cytoplasmic material is enclosed by an isolation membrane ${ }^{59}$ into a membranous organelle, the autophagosome, which can fuse with lysosomes to initiate digestion of the respective material. ${ }^{57}$ This way, autophagy provides resources for biosynthesis and cleans up the cytosol. ${ }^{55,57}$ The autophagosomes are observable by microscopy as vacuole-like, double-membraned bodies. ${ }^{49}$ The mitochondria plays a vital role as the origin of autophagosomal membrane in addition to its role in activating autophagy. Autophagy occurs constantly at low levels in the cell, however, activity is increased at certain conditions such as during nutrient deprivation. Eleven autophagy-related (Atg) genes haven been identified in mammals, prominent ones being Atg8 (LC3) and Atg6 (Beclin1), which initiate the formation of autophagosomal vesicles. ${ }^{48}$ If the mitochondrial production and the cellular concentration of ATP is low, AMPK is activated and can either phosphorylate the serine/threonine-protein kinase UNC51 like kinase 1 (ULK1) directly to upregulate autophagy, or inhibit the mechanistic target of rapamycin complex 1's (mTORC1) inhibition on ULKs by inhibitory phosphorylation of mTORC1s two regulators (tuberous sclerosis complex 2 [TSC2] and regulatory-associated protein 
of mTOR [RAPTOR]), which also leads to a higher rate of autophagy. ${ }^{15}$ As much as scientists want to classify and bring biochemical processes in order, it is not possible to completely separate autophagy and apoptosis. They are not two distinct routes of action, but rather intimately linked. ${ }^{55}$ Efforts to generalize the exact roles and mechanisms have also not been successful, as it appears that the interplay between them is highly complex and varies in cell types, tissue types, and individuals. ${ }^{55}$ Factors that affect autophagy are manifold, greatly relate to nutrient availability $(\mathrm{mTOR}, \mathrm{AMPK})^{46,48,60}$ and the associated hormone signaling ${ }^{57}$ and are also linked to apoptosis, ${ }^{48}$ which has been reviewed by Fan and Zong (2013). To quote their closing remarks:

"autophagy clearly has both pro-survival and pro-death functions, and this is largely dependent on the cell's ability to die by apoptosis [...] When cellular damage is too severe, apoptosis kicks in to eliminate irreparable cells to maintain tissue homeostasis. In cells with defective apoptosis, autophagy may serve as a backup strategy for cellular demise or as a mechanism to promote other forms of cell death, such as necrosis." 55

This interwoven relationship poses a challenge to anyone who wants to study the effects of a compound on autophagy, since markers should ideally be as exclusive to the investigated phenomenon as possible. In the field of autophagy research, scientists aim to differentiate between symptoms that possibly hint to autophagy and actually increased flux through the entire autophagy pathway. ${ }^{61}$ An estimate of LC3 (Atg8) is often used to determine induction or inhibition of autophagy. ${ }^{48}$ AMPK and mTOR phosphorylation can offer information about the activity and probably the effects on autophagy. ${ }^{61}$

\subsection{Hormetic Compounds}

Plant-based substances (phytochemicals) are commonly investigated for hormetic behavior. These compounds - often polyphenolic extracts ${ }^{62}$ that include phytoestrogens, phytosterols, carotenoids, chlorophyll, isothiocyanates, ${ }^{63}$ and flavonoids ${ }^{64}$ - do not hold any nutritional value, since they do not fall into the category of proteins, carbohydrates, or fats. Phytochemicals often display antimutagenic and anticarcinogenic properties, ${ }^{65}$ which sparked the recommendation to ingest at least five servings of vegetables and fruit (sources of phytochemicals) in the hope that these aid in 
the prevention, retardation, treatment, or cure of certain diseases, including cancer. ${ }^{1,6,66}$ Interestingly, due to their biphasic behavior, hormetic substances can, at lower doses, protect cells from DNA damage and the subsequent development of cancer, and at higher doses, be used as therapeutic supplements against cancer due to their cytotoxicity. ${ }^{3}$ Bits and pieces of the exact modes of action for phytochemicals are known, but the whole picture remains to be clarified, ${ }^{5}$ and the question persists if they share a common mode of action in the concept of hormesis, or if each phytochemical triggers its own profile of distinct beneficial processes inside the cell. ${ }^{66}$ Some common affected targets have been summarized by Murugaiyah and Mattson (2015), which include AMPK and mTOR. ${ }^{1}$<smiles>COc1cc(/C=C/C(=O)CC(=O)/C=C/c2ccc(O)c(OC)c2)ccc1O</smiles><smiles>O=c1c(O)c(-c2ccc(O)c(O)c2)oc2cc(O)cc(O)c12</smiles><smiles>[R][C-]=Cc1ccc(O)cc1/C=C/c1cc(O)cc(O)c1</smiles><smiles>O=C(OC1Cc2c(O)cc(O)cc2OC1c1cc(O)c(O)c(O)c1)c1cc(O)c(O)c(O)c1</smiles>

Epigallocatechin-3-gallate

Figure 4| Chemical structures of curcumin, resveratrol, quercetin, and epigallocatechin-3-gallate.

\subsubsection{Quercetin}

Quercetin is a flavonoid derived from nuts, seeds, olive oil, vegetables, herbs, buckwheat, and teas, and is highly abundant in the human diet. ${ }^{3,67-69}$ The main properties ascribed to quercetin are associated with ROS and their potential damage to tissue. As an electron donor to $\operatorname{ROS}^{67}$ and a chelator for certain metal ions, quercetin achieves anti-oxidant results, and therefore has been shown to decrease the incidence of DNA damage and the chances of cancer development. ${ }^{3}$ Additionally, quercetin can induce expression of the DNA repair protein 8-oxyguanine DNA 
glycosylate (hOGG1) $)^{67,70}$ and activates the antioxidant glutathione. ${ }^{67,69}$ Induction of metallothioneins (MT) by quercetin has been reported to protect against heavy metal toxicity in a liver carcinoma model. ${ }^{71}$ These properties are observed at doses below $40 \mu \mathrm{M},{ }^{3}$ although Kim et al. (2009) observe antioxidant effects up to $100 \mu \mathrm{M} 30$ minutes post-exposure. Tan et al. (2009) found that simultaneously decreased levels of the anti-apoptotic proteins survivin and Bcl-2 as well as increased levels of p53 and increased activity of caspase-3/-9 cause cytotoxicity in HepG2 cells, but their data did not support hormetic behavior. ${ }^{72}$ There is no clear agreement on quercetin's hormetic properties, which is why the compound should be investigated more thoroughly.

\subsubsection{Epigallocatechin Gallate}

The green tea, black tea, and red wine component epigallocatechin gallate showed a beneficial antioxidative character in several studies, ${ }^{73}$ and has additionally been found to have anticarcinogenic, anti-angiogenic, as well as anti-proteolytic features, ${ }^{74}$ especially in cases of ethanol and hypoxia induced damage, where epigallocatechin gallate ameliorated the effects. ${ }^{73,74}$ In HepG2 cells, induction of autophagy has been assigned to an exposure of $40 \mu \mathrm{M}$ of catechin, ${ }^{75}$ while Shen et al. (2014) reported a decrease in autophagy induction of approximately $25 \%$ after a 24 and 48 -hour exposure of $87 \mu \mathrm{M}$ and by $45 \%$ after 78 hours. ${ }^{76}$ Additionally, $174.5 \mu \mathrm{M}$ and $262 \mu \mathrm{M}$ inhibited metabolic activity in the same cell line by $40-45 \%$ after 24 hours, $65 \%$ after 48 hours, and $70 \%$ after 72 hours, respectively. Hormesis tends to be observed at lower concentrations than the ones listed here, so an expansion of the dosing range into smaller concentrations might reveal hormetic behavior. For a review of epigallocatechin gallate's origin, bioavailability, see Roberto et al. (2016). ${ }^{77}$

\subsubsection{Curcumin}

Derived from turmeric, curcumin is a yellow to orange colored powder that has been extensively studied in the last years, especially with respect to the prevention and treatment of cancer. ${ }^{78}$ Cellular effects found in vitro and in vivo in varying cell lines include the induction of mitochondria mediated apoptosis, ${ }^{78-80}$ autophagy, ${ }^{80,81}$ disruption of mitochondrial membrane potential, ${ }^{79}$ increase in calcium ion concentration, ${ }^{79}$ antioxidant characteristics through binding of 
Nrf2 ${ }^{82}$ and prooxidant characteristics at higher doses. In HepG2 cells, Wang et al. (2011) observed a decline in cell viability response by $20 \%$ starting at $5 \mu \mathrm{M}$, almost linearly decreasing until onefifth of the control values at $20 \mu \mathrm{M} .^{79}$ In a different paper, Qian et al. (2011) found a $20 \%$ increase in cell viability after a 12-hour exposure to $5 \mu \mathrm{M}$, while all other exposures of 24 and 36 hours to 20 and $50 \mu \mathrm{M}$ either did not affect the cell viability compared to controls, or decreased cell viability. Therefore, curcumin might show hormetic behavior.

\subsubsection{Resveratrol}

Resveratrol is a polyphenol found in peanuts and grapes, predominantly, that has been thoroughly studied for antiproliferative, chemo-preventive, cardio-protective, immune system improving, antiaging, gut health regulating, and antioxidant effects. ${ }^{83-87}$ Marcsek et al. (2007) found slight, but not significant, increase in cell proliferation after exposing HepG2 cells to 0.1 to $100 \mu \mathrm{M}$ for 24 hours. After 48 hours, cell viability was unaffected by concentrations up to $12.5 \mu \mathrm{M}$ but declined from there to about $50 \%(100 \mu \mathrm{M})$, and 72 -hour exposures gave similar results. ${ }^{83}$ Plauth et al. (2016) on the other hand found increased cell viability up to $100 \mu \mathrm{M}$ in the same cell line, although exposure time was only 16 hours. ${ }^{84}$ An increase in signal from MTT assays by $20 \%$ for resveratrol concentrations between 30 and $50 \mu \mathrm{M}$ after 24 hours was reported, but the effect did not last for an exposure of 48 hours. ${ }^{88}$ Such proliferative effects have been observed in a variety of human cancer cell lines and preventive effects for other diseases, such as Alzheimer's or gastric ulcers, have also been described. ${ }^{89}$ Additionally, co-exposure of resveratrol with, for example, matrine or formaldehyde, decreased the detrimental effects of the cytotoxic substances. ${ }^{83,90}$ Between the three previously cited papers, it is clear that resveratrol causes a hormetic adaption, however, exact concentrations vary mainly because the exposure times are not matched. A more detailed study into these two aspects should be able to resolve uncertainty. 


\section{Experimental Design, Methods, and Materials}

\subsection{Experimental Design}

This work aims to clarify the concentration and exposure duration dependence in hormetic behavior for several compounds. For this thesis, four compounds were chosen, based on literature review, and human hepatocyte carcinoma cells were exposed to varying concentrations. The first set of experiments was meant to screen these four compounds for the best concentration range to observe potentially biphasic behavior. Depending on the results, compounds were then selected for additional studies involving a series of different exposure times to address the duration dependence. Concentration ranges were kept constant throughout this part to ensure complete comparability of data.

\subsubsection{In vitro Model}

For the herein described experiments, a human hepatocyte carcinoma cell line (HepG2) was chosen as the in vitro model. The mammalian liver hosts major phase I and phase II metabolism of xenobiotics, and offers detoxification capabilities, but can also yield metabolites with increased harm for the system. Therefore, metabolic experiments from this cell line can deliver important information about the pharmacokinetic nature of phytochemicals. In addition, the cell line provides insight into liver carcinoma-specific metabolism and how the investigated compounds can affect cancer cell survival. ${ }^{5}$ Although single-cell experiments give a more exact picture on metabolic changes, ${ }^{12}$ measurements from a cell population can at least suggest trends and point into the right direction for further studies.

\subsubsection{Cell-based Assays}

Four substances were chosen due to their previously reported hormetic behavior or their potential for hormetic behavior: Curcumin, epigallocatechin gallate, resveratrol, and quercetin. The initial experiments aim to characterize appropriate concentration ranges, optimize assay conditions, and rule out compounds that give inconsistent results. Subsequent experiments monitor the metabolic activity and plasma membrane degradation across the determined concentration range. Exposure 
duration dependence was examined through measurements six, twelve, 24, 48, and 72 hours after a one-time dose of the compound.

Concentration ranges investigated were: 0.01 - $500 \mu \mathrm{M}$ curcumin and epigallocatechin gallate, $0.01-2000 \mu \mathrm{M}$ resveratrol and quercetin. Quercetin's effects greatly depend on the route of metabolism in the body, which is vastly branched. ${ }^{3}$ Isorhammetin and tamarixetin are two wellstudied metabolites, but for the purpose of this study, pure quercetin was used, since it appears to have the largest anti-oxidant effect. ${ }^{3}$ Based on Lüer et al.'s (2014) demonstration that synthetic and natural curcumin have the same cellular effects, synthetic curcumin was employed in experiments. ${ }^{91}$ While resveratrol exists in three forms in red wine (trans-, cis-, and dihydroresveratrol), trans-resveratrol makes up the predominant constituent, which is why that species was chosen for investigation. ${ }^{92}$ Epigallocatechin 3-gallate was employed for similar reasons (abundance in tea) and will further be referred to as epigallocatechin gallate.

Effects on cell viability after an exposure of 24 hours are assessed with the widely used MTT assay. Active cellular metabolism in live cells is commonly measured making use of MTT tetrazolium (3,[4,5-dimethylthiazol-2-yl]-2,5-diphenyl-tetrazolium bromide), which is converted to formazan by reducing molecules inside the cell. ${ }^{93}$ The exact mechanism is not known yet, but it is assumed that MTT enters the cell through endocytosis and is reduced by several substrates, including succinate, malate, glutamate, NADH, and NADPH. ${ }^{93}$ Liu et al. (1997) showed, however, that the reduction of MTT does not only rely on active mitochondria, as has been widely stated. Therefore, this assay merely measures metabolic production of reducing substrates. The amount of formazan increases linearly with cell number, presuming their metabolism is the same. Varying metabolic rates, for example in cells at different stages, can influence linearity and skew results. ${ }^{94}$ MTT is usually dissolved in buffer, such as PBS, at a concentration of approximately $5 \mathrm{mg} / \mathrm{mL}^{95}$ and diluted ten-fold in the assay well. Formazan accumulates as a purple crystalline precipitate over several hours; therefore, plates need to be incubated at $37{ }^{\circ} \mathrm{C}$ to increase sensitivity and signal stability. The blue-purple crystals are then solubilized, with solutions ranging from isopropanol and dimethylsulfoxide to preparations of SDS in DMSO, ${ }^{94}$ and the relative concentration of formazan can be measured through absorbance at $570 \mathrm{~nm}$. Assay kits supplying an MTT solution and detergent are commercially available. 
Exposure effects leading to cell death through plasma membrane integrity are studied with ethidium-D1 homodimer When cells undergo cell death after a xenobiotic insult, the cell membrane is found to be compromised, which equals an increase in premeability. ${ }^{96}$ This can be used to label dead cells with a - in principle - cell impermeable compound, such as ethidium-D1 homodimer, which binds to nucleic acid once it entered into the cytosol of a damaged cell. ${ }^{97}$ The free nucleic acids is another sign of a cell moving towards cell death, especially during coordinated cell death (apoptosis), since the nucleus undergoes sequestration and the DNA is broken down. ${ }^{49}$ The homodimer chelates the double stranded nucleic acids ${ }^{98}$ and exhibits a red fluorescence ${ }^{99}$ that can be measured at excitation/ emission wavelength 530/645 nm.

\subsection{Methods and Materials}

\subsubsection{Materials}

HepG2 cells were acquired from ATCC (ATCC ${ }^{\circledR}-\mathrm{HB}-8065^{\mathrm{TM}}$ ). Cell culture media was prepared from Dulbecco's Modified Eagle's Medium (Sigma-Aldrich) in deionized water from a EMD Milipore DirectQ Water System. D-(+)-glucose, sodium pyruvate, L-glutamate monosodium hydrate, and sodium bicarbonate were purchased from Sigma-Aldrich. 100X solutions of streptomycin and penicillin were acquired from Corning, HyClone fetal bovine serum defined from Thermo Scientific and HEPES from Fisher BioReagents. 0.05\% trypsin with $0.53 \mathrm{mM}$ EDTA (1X), Costar polystyrene tissue culture treated clear flat bottom 96 well plates (low evaporation lid), Costar polystyrene tissue culture treated black with clear flat bottom 96 well plates, and T75 cell culture flasks with vented caps were procured through Corning. HPLC grade methanol was purchased from EMP, DMSO from Fisher BioReagents, 0.4\% trypan Blue from MP, ethidium

homodimer-1 from Invitrogen Molecular Probes, and the TACS ${ }^{\circledR}$ MTT Cell Proliferation Assay Kit from Trevigen. Quercetin, (-)-epigallocatechin gallate, and trans-resveratrol, were obtained from Cayman Chemical Company, while curcumin was purchased from Acros Organics. 


\subsubsection{Cell Culture}

HepG2 (human hepatocellular carcinoma-derived) cells were cultured in cell line specific medium (DMEM, $2 \mathrm{~g} / \mathrm{L}$ D-glucose, 10\% fetal bovine serum, $100 \mathrm{mg} / \mathrm{mL}$ streptomycin, $100 \mathrm{U} / \mathrm{mL}$ penicillin, $1 \mathrm{mM}$ sodium pyruvate, $2 \mathrm{mM}$ L-Glutamate, $5 \mathrm{mM}$ HEPES, and $24 \mathrm{mM}$ sodium bicarbonate) and maintained at $37{ }^{\circ} \mathrm{C}$ in humidified, $5 \% \mathrm{CO}_{2}$ atmosphere. Cells were passaged at $70 \%-90 \%$ confluence, using trypsin EDTA as lifting agent. Cell density was determined after

trypan blue staining on a Reichert Bright-Line ${ }^{\mathbb{R}}$ Improved Neubauer hemocytometer in $10 \mu \mathrm{L}$ of a 1:1 dilution of cell solution in staining reagent ( $20 \mu \mathrm{L}$ each). For all assays, approximately 40000 cells $/ 100 \mu \mathrm{L}$ were seeded into 96 well plates (clear for absorbance assays, black with clear bottoms for fluorescence) in indicator-free medium and allowed to reattach for 24 hours before dosing.

\subsubsection{Dosing}

Stock solutions of all compounds were prepared in DMSO in accordance with the substances' solubility: $10 \mathrm{mM}$ and $50 \mathrm{mM}$ curcumin, $50 \mathrm{mM}$ epigallocatechin gallate, $100 \mathrm{mM}$ resveratrol, and $100 \mathrm{mM}$ quercetin.

100X dosing solutions were freshly mixed by diluting appropriate amounts of stock solution in DMSO, which were subsequently diluted 100 -fold in cell culture medium to yield the final dosing concentrations. Curcumin: $0.01,0.1,0.5,1,5,10$, and $50 \mu \mathrm{M} .100$ and $500 \mu \mathrm{M}$ dosing solutions were created by directly diluting the $10 \mathrm{mM}$ or $50 \mathrm{mM}$ stock solution 1:100 in cell culture medium. Epigallocatechin gallate: $0.01,0.1,1,5,10,25,50,70,100,150,200,250,300$, and $400 \mu \mathrm{M}$. $500 \mu \mathrm{M}$ dosing solutions were created by directly diluting the $50 \mathrm{mM}$ stock solution 1:100 in cell culture medium. Quercetin and resveratrol: 0.01, 0.1, 1, 5, 10, 25, 50, 70, 100, 200, 400, 500, 600, and $800 \mu \mathrm{M}$. $1000 \mu \mathrm{M}$ dosing solutions were created by directly diluting the $100 \mathrm{mM}$ stock solution 1:100 in cell culture medium, $2000 \mu \mathrm{M}$ dosing solutions were created by directly diluting the $100 \mathrm{mM}$ stock solution 1:50 in cell culture medium. All dosing solutions had a final DMSO concentration of $1 \%$ or $2 \%$. Dosing solutions used in different assays may not include all listed concentrations and can vary between plates.

24 hours after seeding, spent cell culture medium was aspirated and discarded, and cells were supplied with $100 \mu \mathrm{L}$ fresh culture medium in the form of the dosing solutions. 96 well plates were 
either incubated for the respective exposure time at $37^{\circ} \mathrm{C}$ in humidified, $5 \% \mathrm{CO}_{2}$ atmosphere or, for real-time measurements, covered with plate tape and kept at $37^{\circ} \mathrm{C}$ in the plate reader.

\subsubsection{Assays}

All plates were evaluated using a Tecan InfiniteM100 plate reader (Tecan US, Raleigh, NC) and Tecan i-control 1.10 software.

\subsubsection{MTT Assay}

Cell viability assays were performed using the TACS $^{\circledR}$ MTT Cell Proliferation Assay Kit (Trevigen) per manufacturer's protocol. Briefly, at the end of the respective exposure time, $10 \mu \mathrm{L} /$ well MTT reagent (3,[4,5-dimethylthiazol-2-yl]-2,5-diphenyl-tetrazolium bromide) were added. After six hours of incubation at $37^{\circ} \mathrm{C}, 100 \mu \mathrm{L}$ detergent were dispensed in each well, the plates covered in aluminum foil and stored in a dark cupboard for twelve hours. Absorbance was then read from the bottom at $570 \mathrm{~nm}$. Controls for this assay included untreated $1 \%$ and $2 \%$ DMSO vehicle controls (where necessary), as well as blank controls without cells at each concentration for background absorbance, since some substances showed an increased absorbance with increased concentration. Control and experimental wells were treated identically throughout the assay. Average absorbance values were corrected for background absorbance from the blank controls and normalized to untreated vehicle controls wells.

\subsubsection{Plasma Membrane Degradation Assay}

Plasma membrane degradation assays were performed using ethidium-D1 homodimer. $1 \mathrm{mg}$ was dissolved in $20 \%$ aqueous DMSO to a concentration of $2 \mathrm{mM}$. After the respective incubation period, $100 \mu \mathrm{L}$ of $4 \mu \mathrm{M}$ ethidium D-1 homodimer in culture medium were added to each well for endpoint experiments and kept at $37{ }^{\circ} \mathrm{C}$ in humidified, $5 \% \mathrm{CO}_{2}$ atmosphere for 20 minutes. Fluorescence was measured from the bottom with excitation at $530 \mathrm{~nm}$ and emission at $645 \mathrm{~nm}$. Controls for this assay included untreated 1\% DMSO vehicle controls, blank controls without cells at each concentration, and control wells of $100 \%$ dead cells (removal of reaction mixture and 
addition of $100 \mu \mathrm{L} 70 \%$ methanol in medium 30 minutes prior to the end of the respective incubation period) for maximum signal. Control and experimental wells were treated identically throughout the assays. Average fluorescence values were corrected for background fluorescence through blank control values and normalized to maximum signal responses (unless otherwise specified).

\subsubsection{Data Evaluation and Statistical Analysis}

Data from cell-based assays were exported and analyzed with Prism 5.03 (GraphPad), values are reported as the mean \pm standard error of the mean. For cell viability assays, values were first corrected by subtracting the corresponding blanks and then normalized to the vehicle control (no treatment, assumed 100\% live). For plasma membrane degradation assays, values were first corrected by subtracting the corresponding blanks and then normalized to the dead control (70\% methanol 30 minutes prior to the end of the exposure time, assumed 100\% dead). Statistical significance was determined using one-way ANOVA with Bartlett's test for equal variances and Bonferroni's Multiple Comparison Test. The following notation is used to report p-values (unless otherwise specified): ${ }^{*} \mathrm{p} \leq 0.05, * * \mathrm{p} \leq 0.01, * * * \mathrm{p} \leq 0.001$ compared to vehicle control; ${ }^{*} \mathrm{p} \leq 0.05$, ${ }^{\# \#} \mathrm{p} \leq 0.01,{ }^{\# \#} \mathrm{p} \leq 0.001$ compared to the previous concentration, ${ }^{\circ} \mathrm{p} \leq 0.05,{ }^{\circ} \mathrm{p} \leq 0.01,{ }^{\circ \circ} \mathrm{p} \leq 0.001$ compare to the previous exposure time. 


\section{Results and Conclusion}

\subsection{Substance Screening}

Human hepatocyte carcinoma cells (HepG2) were exposed to varying concentrations of epigallocatechin gallate, resveratrol, quercetin and curcumin for 24 hours. Effects on metabolic activity and plasma membrane integrity were assessed using MTT (3,[4,5-dimethylthiazol-2-yl]2,5-diphenyl-tetrazolium bromide) and ethidium-D1 homodimer, respectively. Results are summarized in Figure 5 and Table 1. Substances were screened for hormetic behavior, e.g. an increase in metabolic activity above controls level and a simultaneous decrease in plasma membrane degradation at lower concentrations; a decrease of metabolic activity associated with an increase in plasma membrane degradation at higher concentrations.

\subsubsection{Epigallocatechin Gallate, Quercetin, and Curcumin}

Effects of epigallocatechin gallate treatment on metabolic activity at concentrations up to $10 \mu \mathrm{M}$ were unchanged from basal control levels. From 25 to $500 \mu \mathrm{M}$, the metabolic activity increased in the mean by 28 to $86 \%$. However, variability in the four independent experiments was high and the variance in means did not show a significant change at higher concentrations. Additionally, no decrease in metabolic activity was observed. Plasma membrane degradation results showed a decrease compared to vehicle controls at 25 and $50 \mu \mathrm{M}$. Data points from higher concentrations consistently gave invalid results and are not included here. In theory, a decrease in plasma membrane degradation in association with an increase in metabolic activity matches hormetic behavior. Nevertheless, variability was considerably too high, especially in MTT results, to recommend epigallocatechin gallate for further duration dependence experiments. Zapf et al. (2015) concluded that an exposure of $4.4 \mu \mathrm{M}$ over twelve, 24, and 48 hours did not decrease cell viability in the same cell line, which the herein presented results support. ${ }^{100}$ However, Shen et al. (2014) reported decreased metabolic activity from 87, 174.5, and $262 \mu \mathrm{M}(25 \%, 45 \%, 45 \%$, respectively) after 24 hours of exposure, ${ }^{76}$ which is partially matched by other studies, ${ }^{101}$ but was not reproduced in the presented experiments. In fact, our results rather suggest an increase in metabolic activity for concentrations above $100 \mu \mathrm{M}$. The typical hormetic dose response behavior was not observed for the investigated cell line. Naponelli et al. (2015) reported that 
epigallocatechin gallate induces endoplasmatic reticulum stress in prostate cancer cells, but the cells were able to overcome this stress at least between the first six to twelve hours. After that, $76 \mu \mathrm{M}$ induced anoikis, and $316 \mu \mathrm{M}$ induced cell death. ${ }^{58}$ In its nature as a catechin, epigallocatechin gallate is presumed to owe its beneficial character to the activation of Nrf2, which increases activity of phase II enzymes. ${ }^{6}$ Calabrese et al. (2010) state that various pathways can be influenced by this molecule, including protein kinase $\mathrm{C}, \mathrm{Bcl}-2$ family members, and antioxidant
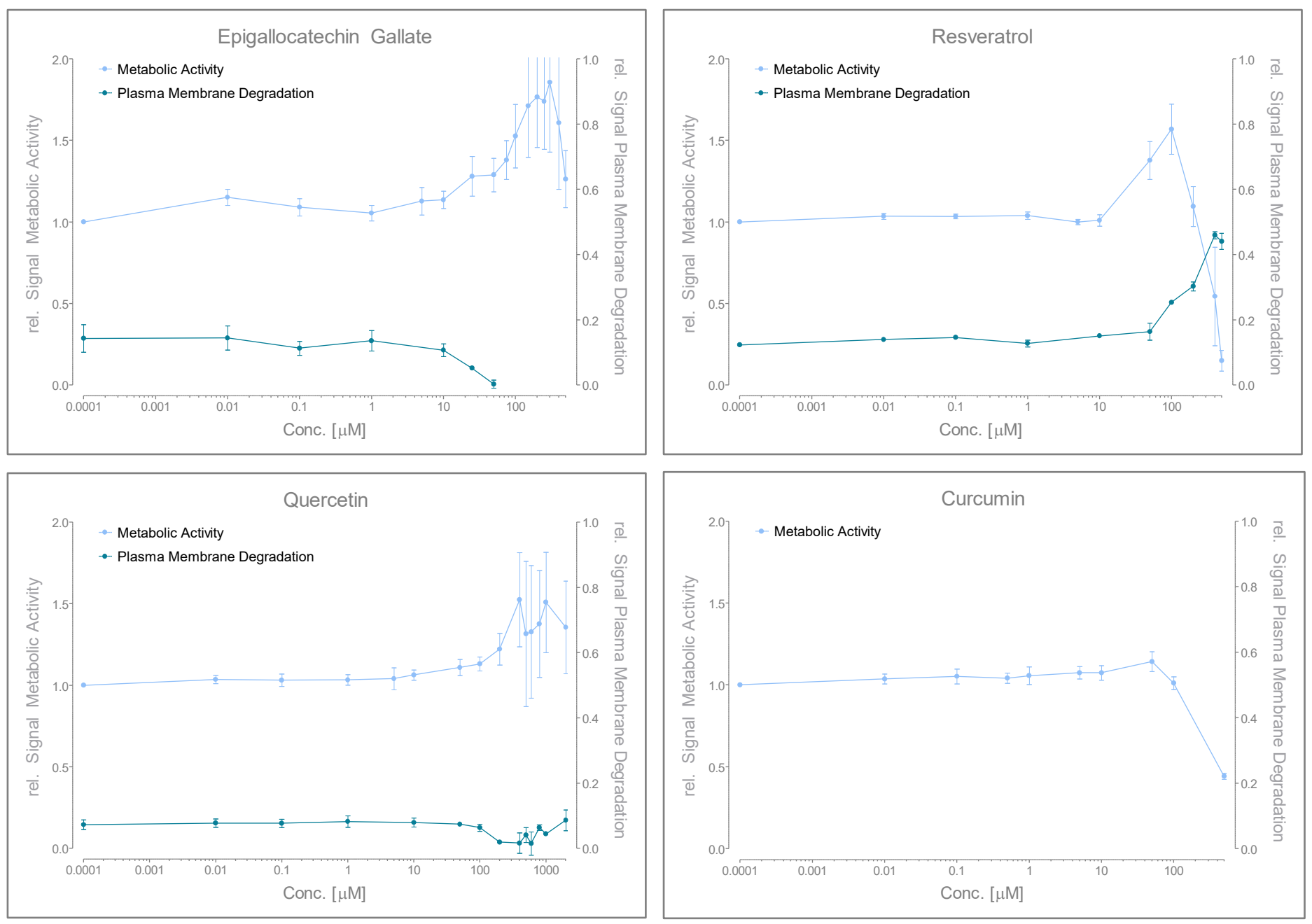

Figure 5| Metabolic activity and plasma membrane degradation after 24-hour exposure to epigallocatechin gallate, resveratrol, quercetin, and curcumin.

HepG2 cells were exposed to varying concentrations of epigallocatechin gallate (top left), resveratrol (top right), quercetin (bottom left), or curcumin (bottom right) for 24 hours. Effects on metabolic activity were assessed using MTT, effects on plasma membrane integrity were assessed using ethidium homodimer-1. Data shown represent the mean and the standard error of the mean from four independent experiments. Experimental values were measured in duplicate, triplicate, quadruplicate, or sextuplicate. 
enzymes. ${ }^{102}$ Ye et al. (2012) found activated SIRT1 signaling (an energy sensor for NAD ${ }^{+}$) when PC12 cells - a rat adrenal gland cell line - were exposed to a cytotoxic compound (MPP $\left.{ }^{+}\right)$ alongside $10 \mu \mathrm{M}$ epigallocatechin gallate, which increased cell viability markedly compared to treatment with the cytotoxic compound alone. ${ }^{103}$ The green tea extract undoubtedly exerts positive effects, but is most likely not a hormetin.

Similar to epigallocatechin gallate, exposure to quercetin did not trigger a change in cellular behavior at low doses up to $10 \mu \mathrm{M}$. From $50 \mu \mathrm{M}$ to $2000 \mu \mathrm{M}$, trends in metabolic activity and plasma membrane degradation complemented each other, however, none of the increases or decreases are statistically significant and the standard error of the mean at higher concentrations was considerably high with regards to metabolic activity. Additionally, quercetin precipitated out of the culture media for concentrations above $500 \mu \mathrm{M}$ soon after dosing, therefore the true concentration in media is unknown. Considering that, no evidence has been found that quercetin exerts hormetic behavior below $800 \mu \mathrm{M}$ and quercetin was not included in additional experiments. While there were observable trends associated with metabolic activity and plasma membrane integrity, the results mostly do not agree with literature values. Tanigawa et al. (2008) found a decrease in MTT response after 24 hours from $20 \mu \mathrm{M},{ }^{104}$ while Tan et al. (2009) observed a considerable decrease in MTT response after 24 hours starting at $12.5 \mu \mathrm{M}$ and an even bigger effect after 48 and 72 hours. ${ }^{72}$ However, Weng et al. (2011), mention no decrease in MTT response up to $50 \mu \mathrm{M},{ }^{71}$ which these experiments support. The problem of quercetin stability in culture media has been addressed previously, ${ }^{68}$ finding that solutions of quercetin above $80 \mu \mathrm{M}$ start to precipitate out at a $\mathrm{pH}$ of 7.4. Therefore, literature values should be taken with a grain of salt if they claim results for anything higher than $80 \mu \mathrm{M}$, as is the case for the results presented here and in Pietsch et al.'s 2011 publication. ${ }^{66}$

No statistically significant change in metabolic activity was observed from curcumin exposure, although the data displays a slight upward trend at $50 \mu \mathrm{M}$ before returning to control level at $100 \mu \mathrm{M}$ and subsequently decreasing to less than $50 \%$ at $500 \mu \mathrm{M}$. Measurements involving plasma membrane degradation were challenging, since curcumin posed an experimental challenge due to its absorption at the experimental wavelength which has been previously discussed. ${ }^{105,106}$ Several control groups (blanks at each concentration including dosing vehicle, blanks of cells with dosing reagent at each concentration without assay reagent, and dead controls for maximum signal) and 
data manipulations were employed assuming to account for the analyte signal, but data evaluation did not yield usable values. Therefore, curcumin was no longer pursued. Literature so far has reported hormesis-like effects on HepG2 cells at low doses of $5 \mu \mathrm{M}$ after twelve hours of exposure, while the same paper does not see hormetic behavior after an exposure of 24 hours, which our results support. ${ }^{81}$ Besides its multitude of positive effects on the human organism, it appears that curcumin does not act like a hormetin, at least not in the investigated liver cancer model. Adenocarcinoma cells (MCF-6) on the other hand seem to increase proliferation up to about $75 \mu \mathrm{M}$ after 24 hours, with no significant decrease in proliferation up to $100 \mu \mathrm{M} .{ }^{68}$ The flavonoid structure allows for a potential inhibition of tyrosine nitration, which would relief excessive nitrosative stress. ${ }^{64}$ Concentrations higher than $40 \mu \mathrm{M}$ exert cytotoxic effects based on quercetin acting as a ROS itself. ${ }^{3}$ Data from breast cancer cells (MDA-MB-231) has been presented, ${ }^{107}$ however, the authors did not see a significant decrease in cell viability until cells were exposed to $100 \mu \mathrm{M}$ for 24 hours. ${ }^{107}$ Vargas and Burd's findings (2010) suggest a mitochondrial and a death-domain apoptotic pathway. ${ }^{3}$ Pietsch et al. (2011) found that doses of 100 and $200 \mu \mathrm{M}$ induced proliferation in C. elegans, but reduced the same metric at a dose of $250 \mu \mathrm{M} .^{66}$

\subsubsection{Resveratrol}

Exposure to resveratrol exhibited a clear trend in metabolic activity and plasma membrane degradation. Doses below $10 \mu \mathrm{M}$ did not change the cellular response compared to basal level in both assays. An increase in metabolic activity of $38 \%$ and $57 \%$ stood out for $50 \mu \mathrm{M}$ and $100 \mu \mathrm{M}$, respectively, although not statistically significant, while the level of plasma membrane degradation steadily increased from a control level of about $15 \%$ (compared to $100 \%$ dead) to $25 \%$ for $100 \mu \mathrm{M}$ and even almost $45 \%$ for the highest doses of 250,400 , and $500 \mu \mathrm{M}$. The change in plasma membrane integrity was statistically significant for $100,250,400$, and $500 \mu \mathrm{M}$. $500 \mu \mathrm{M}$ also significantly decreased metabolic activity to less than $15 \%$ of basal level. In the presented preliminary experiments, resveratrol did not show statistically significant hormetic behavior, however, the standard error of the mean was smaller and data more consistent than other compounds in question. Therefore, HepG2 cells were exposed to varying concentrations of resveratrol for six, twelve, 24,48 , and 72 hours. 
Table 1| Summary of statistically significant changes in metabolic activity and plasma membrane integrity by compound concentration compared to untreated vehicle controls and the previous concentration.

\begin{tabular}{|l|c|c|c|}
\hline \multicolumn{2}{|c|}{ Compared to Untreated Vehicle Control } & \multicolumn{2}{|c|}{ Compared to Previous Concentration } \\
\hline Concentration $[\mu \mathrm{M}]$ & $\begin{array}{c}* \mathrm{p} \leq 0.05 \\
* * \mathrm{p} \leq 0.01 \\
* * * \mathrm{p} \leq 0.001\end{array}$ & Concentration $[\mu \mathrm{M}]$ & $\begin{array}{r}\# \mathrm{p} \leq 0.05 \\
\text { \# } \mathrm{p} \leq 0.01 \\
\end{array}$ \\
\hline
\end{tabular}

Epigallocatechin Gallate

\begin{tabular}{|c|c|c|c|}
\hline Metabolic Activity & \multicolumn{2}{|c|}{ No statistically significant changes } & No statistically significant changes \\
\hline \hline \multirow{2}{*}{ Plasma Membrane Integrity } & $50 \& 75$ & $* *$ & No statistically significant changes \\
\cline { 2 - 4 } & $100-500$ & $* * *$ & \\
\hline
\end{tabular}

\begin{tabular}{|c|c|c|c|c|}
\hline \multicolumn{2}{|c|}{ Resveratrol } \\
\hline \hline \multirow{2}{*}{ Metabolic Activity } & 500 & $* * *$ & \multicolumn{2}{|c|}{ No statistically significant changes } \\
\hline \multirow{2}{*}{ Plasma Membrane Integrity } & 100 & $* *$ & 100 & $*$ \\
\cline { 2 - 5 } & $200-500$ & $* * *$ & 400 & $\# \#$ \\
\hline
\end{tabular}

\section{Quercetin}

\begin{tabular}{|c|l|l|}
\hline Metabolic Activity & No statistically significant changes & No statistically significant changes \\
\hline \hline Plasma Membrane Integrity & No statistically significant changes & No statistically significant changes \\
\hline
\end{tabular}

Curcumin

\begin{tabular}{|c|c|c|c|c|}
\hline Metabolic Activity & 500 & $* * *$ & 500 & \#\#\# \\
\hline
\end{tabular}

\subsection{Resveratrol: Concentration and Duration Dependence}

Preliminary 24-hour exposure experiments in HepG2 cells showed promising results for hormetic behavior associated with resveratrol. To test concentration and exposure duration dependence, the same cell line was exposed to varying concentrations $(0.1-500 \mu \mathrm{M})$ for six, twelve, 24,48 , and 72 hours and the aspects of metabolic activity and plasma membrane integrity were investigated. Results are summarized in Figures 6, 7, and 8, and Tables 2 and 3.

Figure 6 presents data from metabolic activity and plasma membrane degradation measurements for each time point. The panels clearly show an increase in metabolic activity for certain concentrations, while plasma membrane degradation mainly stayed at basal levels until concentration and exposure times increased. 
In detail, cellular responses associated with metabolic activity were approximately the same after six and twelve hours, with an increase in metabolic activity caused by 50 and $100 \mu \mathrm{M}$ by $30 \%$ and $85-89 \%$ of the basal control level respectively. Values obtained from $250 \mu \mathrm{M}$ show a $10 \%$ higher
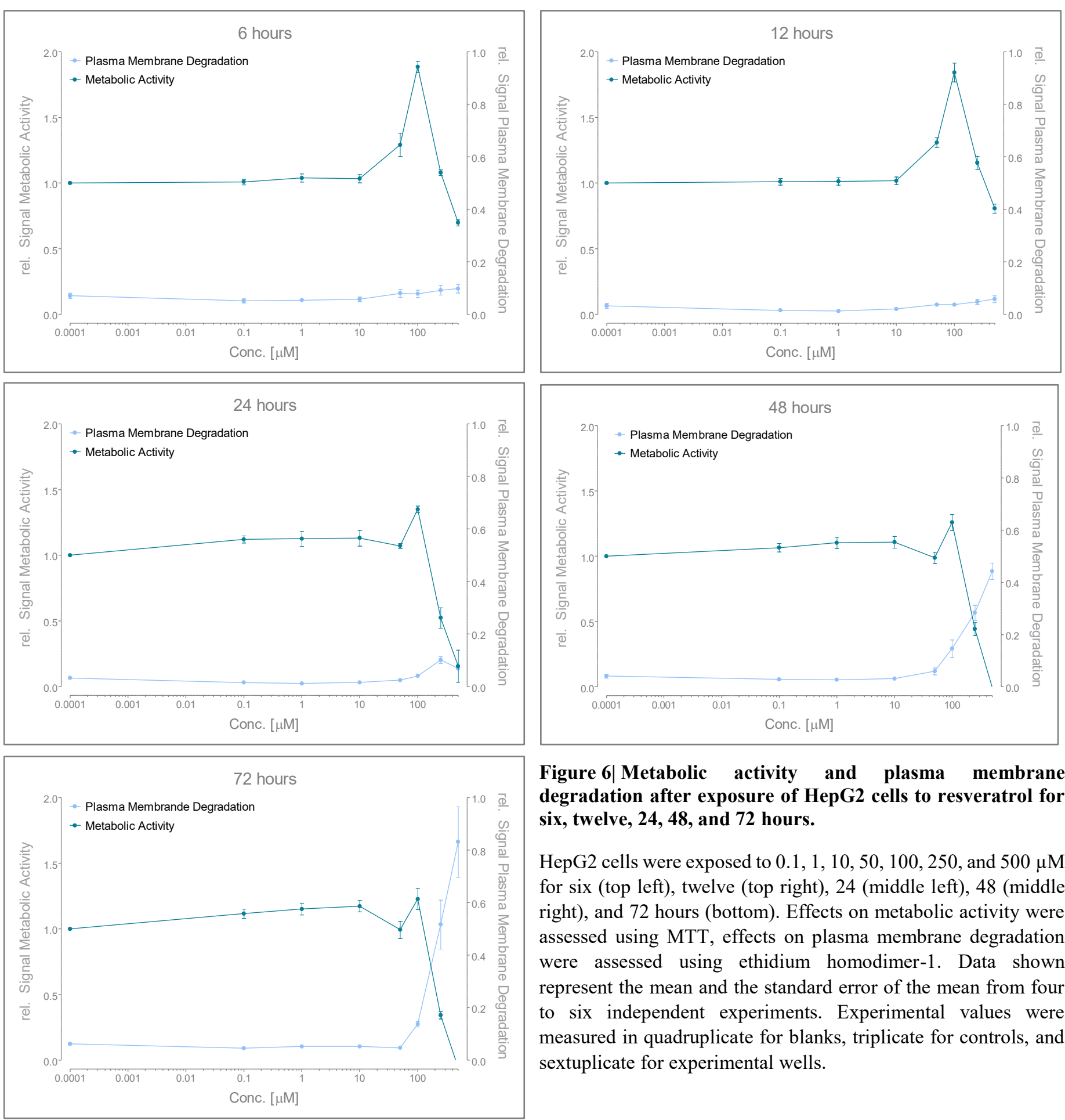

Figure 6| Metabolic activity and plasma membrane degradation after exposure of HepG2 cells to resveratrol for six, twelve, 24, 48, and 72 hours.

HepG2 cells were exposed to $0.1,1,10,50,100,250$, and $500 \mu \mathrm{M}$ for six (top left), twelve (top right), 24 (middle left), 48 (middle right), and 72 hours (bottom). Effects on metabolic activity were assessed using MTT, effects on plasma membrane degradation were assessed using ethidium homodimer-1. Data shown represent the mean and the standard error of the mean from four to six independent experiments. Experimental values were measured in quadruplicate for blanks, triplicate for controls, and sextuplicate for experimental wells. 
metabolic activity, but the variances in the mean were not statistically significant. $500 \mu \mathrm{M}$ resveratrol considerably reduced cellular activity to approximately $75 \%$ of the untreated controls. Metabolic activity noticeably (and statistically significantly) changed between twelve and 24 hours. After 24, 48, and 72 hours, $250 \mu \mathrm{M}$ doses inhibited metabolic activity to less than $50 \%$ on average, and $500 \mu \mathrm{M}$ decreased to less than $15 \% .50 \mu \mathrm{M}$ did not increase the cellular response, but $100 \mu \mathrm{M}$ did for all three later exposure times. The spike of 35\% after 24 hours, $26 \%$ after 48 hours, and 22\% after 72 hours was statistically significant. The disconnect between the early time points of six and twelve hours to the later time points of 24 to 72 hours is especially well presented in Figure 7 (left panel). The right panel in the same figure shows that from 50 to $500 \mu \mathrm{M}$, the cellular behavior follows the same trend, where the dose increases metabolic activity from 6 to 12 hours, and then decreases relative to the previous level from 24 to 72 hours. This change is statistically significant between exposure points from 12 to 24 hours at compound concentrations of $50,100,250$, and $500 \mu \mathrm{M}$. It clearly shows that $100 \mu \mathrm{M}$ has the largest initial influence on the cell, with the highest increase in activity. $50 \mu \mathrm{M}$ has a comparable effect, but in a smaller magnitude. Interestingly, another trend can be observed at lower concentrations between 0.1 and $10 \mu \mathrm{M}$ : with an increase in exposure time, the metabolic activity increased, which seems to be distinctly different than after six and twelve hours, but is not statistically different.
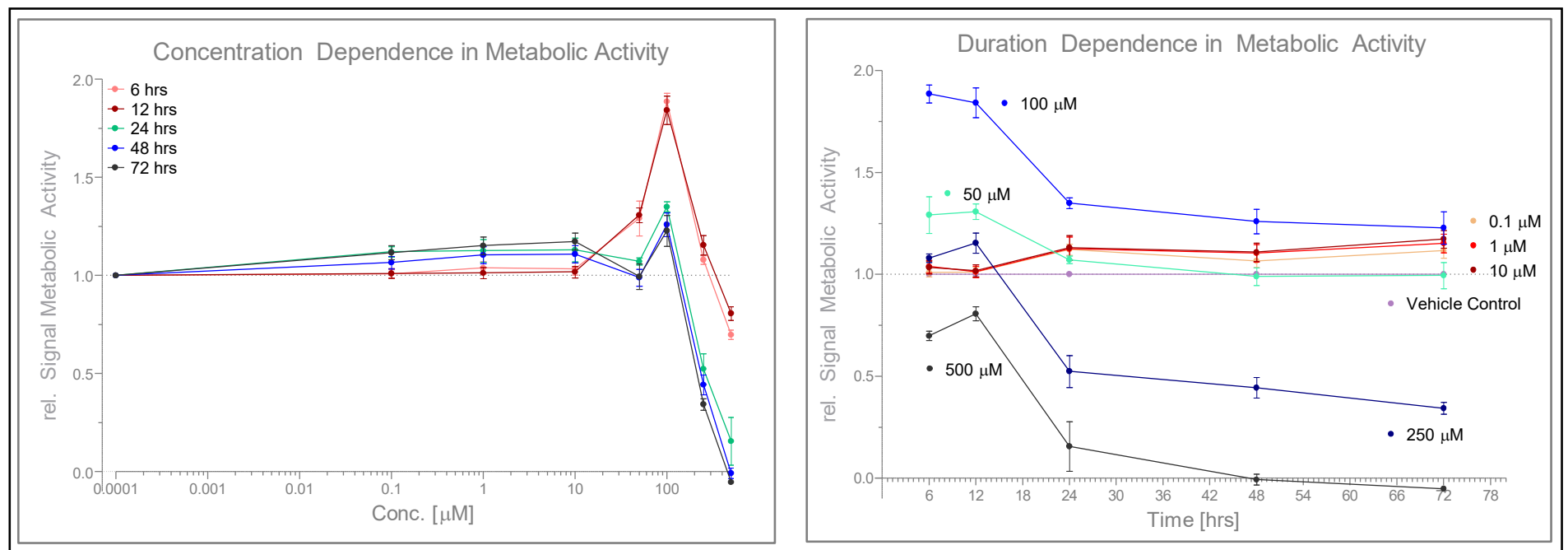

Figure 7| Metabolic activity of HepG2 cells exposed to resveratrol for 6 to 72 hours.

Comparison of the different concentrations (left) and exposure times (right). A clear change in metabolic activity was observed between twelve and 24 hours, especially in response to 50,100, 250, and $500 \mu \mathrm{M}$. A slight increase over time is noticeable for lower concentrations from 0.1 to $10 \mu \mathrm{M}$. Data shown represent the mean and the standard error of the mean from four to six independent experiments. Experimental values were measured in quadruplicate for blanks, triplicate for controls, and sextuplicate for experimental wells. 


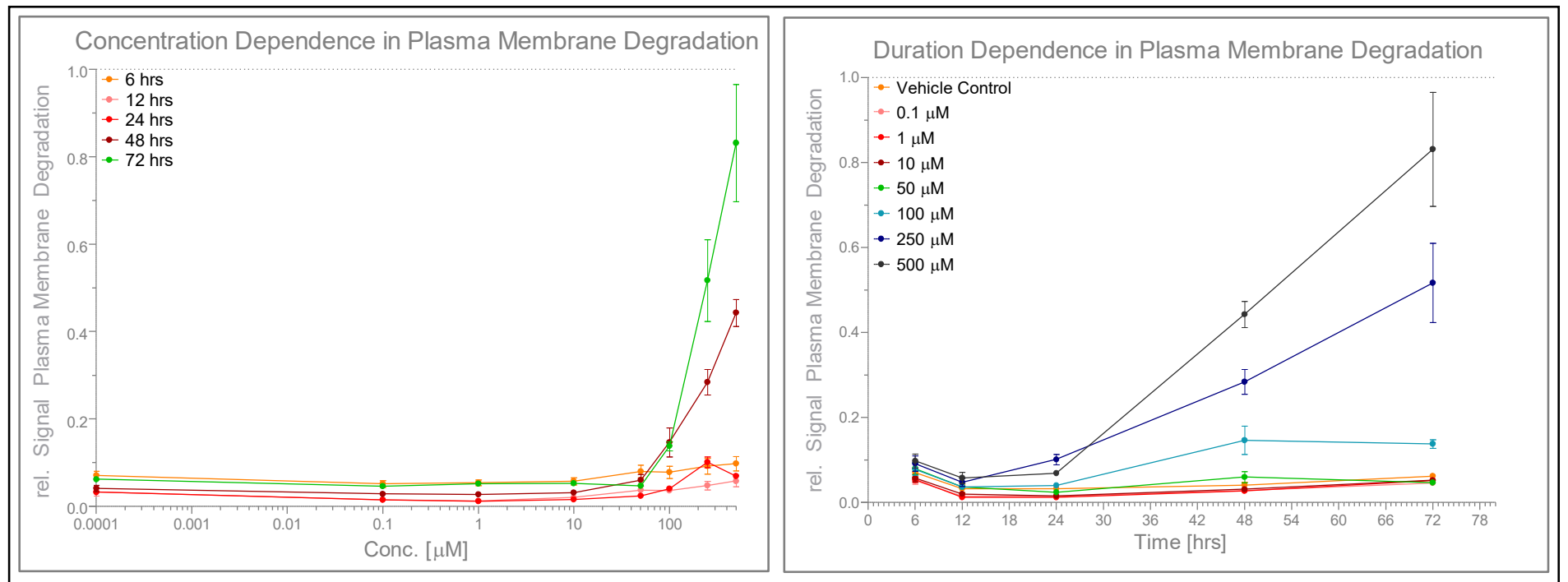

Figure 8| Plasma membrane degradation of HepG2 cells exposed to resveratrol for 6 to 72 hours.

Comparison of the different exposure times (right) and concentrations (left). Plasma membrane integrity was noticeably compromised after 48 hours of exposure to 250 and $500 \mu \mathrm{M}$. An initial decrease in plasma membrane degradation was observed for all concentrations. Data shown represent the mean and the standard error of the mean from four to six independent experiments. Experimental values were measured in quadruplicate for blanks, triplicate for controls, and sextuplicate for experimental wells.

The plasma membrane degradation data points a similar picture. No significant changes in plasma membrane integrity were observed for exposures duration up to twelve hours. After 24 hours, concentrations of 250 and $500 \mu \mathrm{M}$ slightly increased plasma membrane degradation compared to the vehicle control, after 48 hours, 100,250 , and $500 \mu \mathrm{M}$ displayed an increase to 14,28 , and $44 \%$ (of $100 \%$ dead). After 72 hours, 250 and $500 \mu \mathrm{M}$ raised the degree of plasma membrane degradation to 50 and $83 \%$ in the mean (of $100 \%$ dead), respectively. Figure 8 (left) shows that from time point to time point, cellular behavior changed significantly from 24 to 48 hours concerning doses of 100,250 , and $500 \mu \mathrm{M}$, but also between 48 and 72 hours for 250 and $500 \mu \mathrm{M}$ concentrations. When the data was plotted against time, all concentrations initially decreased plasma membrane degradation from six to twelve hours, although not statistically significant, it is a clear trend. Worth noticing is, again, the difference in behavior from low doses, which did not change plasma membrane integrity over time, and high doses, which evidently affected membrane degradation starting at 24 hours. 
Table 2| Summary of statistically significant changes in metabolic activity and plasma membrane integrity between exposure times by resveratrol concentration.

\begin{tabular}{|c|c|c|c|}
\hline & & \multicolumn{2}{|c|}{ Compared to Previous Exposure Time } \\
\hline & Exposure Time & Concentration $[\mu \mathrm{M}]$ & $\begin{array}{c}{ }^{\circ} \mathrm{p} \leq 0.05 \\
\circ \mathrm{p} \leq 0.01 \\
\circ \circ \mathrm{p} \leq 0.001\end{array}$ \\
\hline \multirow{2}{*}{ Metabolic Activity } & \multirow{2}{*}{12 vs. 24 hours } & 50 & ${ }^{\circ \circ}$ \\
\hline & & $100-500$ & ০০০ \\
\hline \multirow{3}{*}{ Plasma Membrane Integrity } & \multirow{2}{*}{24 vs. 48} & 100 & 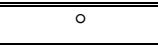 \\
\hline & & $250 \& 500$ & ০০০ \\
\hline & 48 vs. 72 & $250 \& 500$ & 000 \\
\hline
\end{tabular}

Table 3| Summary of statistically significant changes in metabolic activity and plasma membrane integrity after varying exposure times by resveratrol concentration compared to untreated vehicle controls or the previous concentration.

\begin{tabular}{|c|c|c|c|c|}
\hline & \multicolumn{2}{|c|}{ Compared to Untreated Vehicle Control } & \multicolumn{2}{|c|}{ Compared to Previous Concentration } \\
\hline & Concentration $[\mu \mathrm{M}]$ & $\begin{array}{c}* \mathrm{p} \leq 0.05 \\
* * \mathrm{p} \leq 0.01 \\
* * * \mathrm{p} \leq 0.001\end{array}$ & Concentration $[\mu \mathrm{M}]$ & $\begin{array}{c}{ }^{\#} \mathrm{p} \leq 0.05 \\
{ }^{\# \#} \mathrm{p} \leq 0.01 \\
{ }^{\# \# \#} \mathrm{p} \leq 0.001\end{array}$ \\
\hline & \multicolumn{4}{|c|}{ 6-hour Exposure } \\
\hline \multirow{2}{*}{ Metabolic Activity } & $50 \& 100$ & $* * *$ & 50 & \#\# \\
\hline & & & $100-500$ & \#\#\# \\
\hline Plasma Membrane Integrity & \multicolumn{2}{|c|}{ No statistically significant changes } & \multicolumn{2}{|c|}{ No statistically significant changes } \\
\hline & \multicolumn{4}{|c|}{ 12-hour Exposure } \\
\hline Metabolic Activity & $50 \& 100$ & $* * *$ & $50-500$ & \#\#\# \\
\hline \multirow[t]{2}{*}{ Plasma Membrane Integrity } & \multicolumn{2}{|c|}{ No statistically significant changes } & \multicolumn{2}{|c|}{ No statistically significant changes } \\
\hline & \multicolumn{4}{|c|}{ 24-hour Exposure } \\
\hline \multirow{2}{*}{ Metabolic Activity } & 100 & $*$ & 250 & \#\#\# \\
\hline & $250 \& 500$ & $* * *$ & 500 & \#\# \\
\hline \multirow{2}{*}{ Plasma Membrane Integrity } & 250 & "*** & 250 & 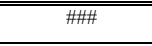 \\
\hline & 500 & $* *$ & 500 & \# \\
\hline & \multicolumn{4}{|c|}{ 48-hour Exposure } \\
\hline \multirow{2}{*}{ Metabolic Activity } & 100 & $* *$ & 100 & \#\# \\
\hline & $250 \& 500$ & $* * *$ & $250 \& 500$ & \#\# \\
\hline \multirow{2}{*}{ Plasma Membrane Integrity } & 100 & +* & 250 & (\#\# \\
\hline & $250 \& 500$ & $* * *$ & 500 & \#\#\# \\
\hline & \multicolumn{4}{|c|}{ 72-hour Exposure } \\
\hline \multirow{2}{*}{ Metabolic Activity } & 100 & $*$ & 100 & $\#$ \\
\hline & $250 \& 500$ & $* * *$ & $250 \& 500$ & \#\#\# \\
\hline \multirow{2}{*}{ Plasma Membrane Integrity } & $250 \& 500$ & **** & 250 & "\#\# \\
\hline & & & 500 & $\#$ \\
\hline
\end{tabular}


With the assumption that the metabolic rate across the sampled cell population is - on average - the same, an increase in metabolic rate from the MTT assay can be seen as an increase in cell proliferation (more metabolic activity equals more metabolically active cells). Four striking observations were made: 1$)$ Low concentrations $(0.1$ to $10 \mu \mathrm{M})$ display no statistically significant change in metabolic activity or plasma membrane integrity, but with increasing exposure time, a trend of a subtle increase in cell proliferation (Figure 6, right panel) and a subtle decrease in plasma membrane degradation (Figure 7, right panel) can be associated with these doses. 2) Higher concentrations (50 to $500 \mu \mathrm{M}$ ) evoke the same trend in HepG2 cells, opposite to the one observed for lower concentrations: Cell proliferation decreases as the exposure time increases; plasma membrane degradation increases as the exposure time increases. 3) Over the time course of 72 hours, the cellular behavior changes for the doses of 50,100, and $250 \mu \mathrm{M}$ : During the first twelve hours, the three concentrations increase metabolic activity; after 24 hours, only $100 \mu \mathrm{M}$ still raises the assay response above control level. The two duration groups (six and twelve hours, 24 to 72 hours) share almost the same response to resveratrol. Therefore, at a time point between twelve and 24 hours, something changes in the cellular metabolism. Plauth et al. (2016) investigated resveratrol's effect on antioxidants and metabolite couples' concentrations, and found a significantly changed intracellular redox environment 16 hours after dosing. 4) When comparing metabolic activity and plasma membrane degradation at $100 \mu \mathrm{M}$, one can see that both increase, especially with an increase in exposure time (Figure 6). This suggests that cellular metabolism increases but the cellular membrane is also increasingly compromised, which might either be rooted in heightened flux in pathways that combat cell death via plasma membrane degradation or the opposite, heightened flux in pathways that eventually cause the permeabilization.

The basis of the hormetic concept was a discovery by Prof. Hugo Schulz, that bacterial metabolism was stimulated. However, it might be important to distinguish between increased metabolism that is beneficial for the cell and increased metabolism that has detrimental effects. With that in mind, the increase in metabolic activity at higher concentrations does not necessarily mean an increase in proliferation. If a cell shifts its metabolism and increases flux through pathways that yield reducing agents then the response to the MTT reagent is heightened. Therefore, the previously made assumption (more metabolic activity equals more metabolically active cells) would not apply here and it would be important to investigate which pathways are induced clarify the situation. 
In general, it is known that resveratrol influences and mimics energy restriction through the interaction with AMPK and SIRT1, ${ }^{88,108,109}$ and triggers apoptosis through increased p53 expression, caspase 9 and 3 activation, and a shift in Bax/Bcl-2 ratio. ${ }^{88,90}$ Long-term exposure studies on mesenchymal stem cell revealed hormetic behavior in the concentrations range from 0.1 to $5 \mu \mathrm{M}$ during a 30 day period, ${ }^{110}$ hepatic stellate cells (GRX) did not experience hormesis after 24 or 120 hours of exposure, just a decrease in cell viability. ${ }^{111}$ These two examples show the importance of a completely resolved concentration and duration profile, especially in differing cell lines.

\subsection{Conclusion}

Four compounds were investigated for their hormetic behavior in a human hepatocellular cancer model in terms of metabolic activity and plasma membrane degradation. Epigallocatechin gallate, quercetin, and curcumin did not show significant hormetic behavior. Resveratrol exerted hormetic behavior in a time- and dose-dependent manner associated with concentrations of 50, 100 and $250 \mu \mathrm{M}$. Low concentrations up to $10 \mu \mathrm{M}$ showed a trend toward hormesis, albeit not statistically significant, which was opposite to the trend observed for higher concentrations. Cellular behavior associated with $100 \mu \mathrm{M}$ resveratrol deserves a short note, since both, metabolic activity and plasma membrane degradation showed higher values. This points to increased signaling and reductive species production associated with pathways that eventually affect plasma membrane integrity. The herein presented data therefore adds to the literature that supports resveratrol as a hormetic compound.

Vargas and Burd (2010) bring up an important point in their review: Most studies on hormetic compounds only involve in vitro and rarely in vivo work. ${ }^{3}$ From in vitro and in vivo work, it is almost too farfetched to give recommendations on supplemental ingestions of specific phytochemicals. Conclusion like these would require a lot more extensive basic research into the biochemical processes associated with each phytochemical. One needs to account for clearing rates in a cell, residence times in a cell, metabolism until the compound reaches the target cell, the ultimate concentration inside the cell, and the individual variability in metabolism rate. Especially since, if a compound exhibits hormetic features, a low concentration (aka not enough of the phytochemical ingested) can have the exact opposite outcome than the desired one. This concern 
has already been voiced by Calabrese et al. (2010): with respect to anticarcinogenic characteristics, a low dose increases instead of decreases the risk of tumor cell growth. ${ }^{89}$ Hormesis is undoubtedly a phenomenon that requires more in-depth attention and better method design. The two main questions, if there is a universal underlying pathway for hormesis, or if a compound triggers its own profile of distinct beneficial processes inside the cell, have not been answered yet, despite the growing literature on hormesis. The example of resveratrol, however, shows how important it is to incorporate a wide range of concentrations and include several more time points (exceeding the norm of 24 hours). 


\section{Future Directions}

Resveratrol causes a noticeable switch in cellular behavior in HepG2 cells between 12 and 24 hours of exposure, significantly different especially at concentrations from 50 to $250 \mu \mathrm{M}$. These findings open the floor to studies that further explore the metabolic basis of hormesis associated with resveratrol. Future experiments should include the assignment of exact post exposure timepoints with real-time assays, to pinpoint when signaling in the cell changes, and consecutive analysis of metabolic markers at these times.

\subsection{Assigning Crucial Energetic Signaling Timepoints}

Since virtually every metabolic pathway requires energy, changes in cellular energy production, and changes in cellular ATP, can be a clue for an adaptive change. Luciferase assays have been used to determine the concentration of ATP in cell lysate and to verify cell viability in endpoint assays, ${ }^{94}$ however, an experiment aiming to find specific time points would have to be a real-time assay. Vrana et. al (2014) used sets of simple cell-based real-time assays in combination with mathematical loops (accounting for aerobic and anaerobic energy metabolism) to estimate the relative intracellular ATP concentration and therefore define the cell's metabolic energy state. ${ }^{112}$ Extracellular oxygen consumption and intracellular NADH were measured kinetically for 24 hours and the data fed into the following expression to calculate theoretically available energetic phosphate:

$$
\begin{gathered}
\text { If } 6\left[\mathrm{O}_{2}\right]_{\text {sample }}-2[\mathrm{NADH}]_{\text {sample }}>0 \\
\text { Then } \mathrm{PO}_{4}=\frac{6\left[\mathrm{O}_{2}\right]_{\text {sample }}-2[\mathrm{NADH}]_{\text {sample }}}{4} \\
\text { Else } \mathrm{PO}_{4}=\frac{[\mathrm{NADH}]_{\text {sample }}}{4}
\end{gathered}
$$

In theory, the concept can be expanded to eventually calculate the actual concentration of ATP per cell, using two cell based assays, one to monitor cell density in real time (for example RealTime$\mathrm{Glo}^{\mathrm{TM}}$ ), and another one to measure ATP at distinct endpoints (for example CellTiter-Glo ${ }^{\circledR} 2.0$ ). 
Both of these assays are based on a bioluminescent signal, which provides the option to run experiments in white or black (if multiplexed with fluorescence based assays) 96 well plates and conveniently obtain data from a plate reader or luminometer.

RealTime-Glo ${ }^{\mathrm{TM}}$, for example, has been used to validate cellular health in tumor resistance experiments, ${ }^{113}$ investigate the cytotoxicity of bacterial biofilms from wound dressings, ${ }^{114}$ or study glucose uptake in a multiplexed assay. ${ }^{115}$ The basis of the kit is the conversion of a luciferase prosubstrate (identity proprietary to Promega) into an active luciferase substrate if taken up into a viable cell. The reducing environment inside the cell facilitates conversion, the substrate exits the cell into the medium where it causes luminescence through the interaction with luciferase. ${ }^{116}$ This way, the signal correlates with active metabolism inside a cell, or put differently, with the production of reducing molecules, such as NADH or FAD, and the manufacturers claim a linear increase in signal with cell density. ${ }^{117}$ Since the substrate is used up by the luciferase, the signal does not compound over time, which increases the accuracy of real-time measurements and provides a big advantage over conventional cell viability assays, such as Calcein AM, in addition to the nontoxic nature of the RealTime-Glo ${ }^{\mathrm{TM}}$ reagents. With this assay, it would be possible to determine the cell number over a given exposure time, granted a standard curve of known densities would be prepared and measured right before the kinetic measurement, ideally in the same plate. Then, available energetic phosphate/cell could be estimated:

$$
\text { available } \mathrm{PO}_{4}=\frac{\mathrm{PO}_{4}}{\text { cell density }}
$$

The second assay, in varying version of the product, has been employed by several studies to measure cell viability. ${ }^{84,113,118-120}$ It can also be used to estimate cell density, ${ }^{121}$ or just simply measure the content of ATP itself, ${ }^{122}$ since the assay is based on the reaction of ATP with the substrate luciferin, which results in a bioluminescent signal directly correlated with the concentration of the energy carrier inside a cell. This can be used to compare the estimated available energetic phosphate, to the actual available triphosphate nucleotide. CellTiter-Glo ${ }^{\circledR} 2.0$ features a solution-mix that contains cell lysis buffer and luciferin as assay reagent. With this solution, the separate cell lysis step and the consecutive centrifugation to obtain ATP in just the lysate is eliminated and the relative amount of ATP can be directly measured in the 96 well reaction plate. A calibration curve of known amounts of analyte can add the important quantitative aspect. 
Since the assay is destructive and only allows for endpoint measurements, specific time points (such as six, twelve, and 24 hours for a 24-hour kinetic experiment) should be chosen to measure definite amounts of adenosine triphosphate. The real ATP can then be compared with the estimated concentration at the same time point, a correction factor can be calculated, and finally it should be possible to convert the entire 24 hour estimated data into real ATP/cell. Graphic visualization in a contour plot heat map and calculation of bifurcation points ${ }^{112}$ can aid in the identification of critical time points of changes in energetic metabolism.

\subsection{Resolve Metabolic Switches in Cellular Energy Metabolism}

To understand the fundamental events that change a cell's behavior after exposure to a xenobiotic, several questions need to be addressed: If the cell increases ATP production, which pathways are increased in activity? Are other pathways decreased in activity? If the cell decreases ATP production, is it bound to die shortly after or does it stay in a lower energetic state and survives? With respect to resveratrol and its hormetic character, two cellular mechanism are of interest especially when it comes to hormesis: autophagy and apoptosis.

Once critical time points are identified, experiments should focus on endpoint assays at these times points to study changes in certain signaling markers. As it is still unclear if common pathways cause hormetic behavior, such as apoptosis and autophagy, or if a compound triggers its own profile of distinct beneficial processes inside the cell, several factors could and should be studied. Kits that label initiator and effector caspases are widely available, as well as antibodies to quantify Atg, which should give a good understanding of the downstream effects for the pathways of autophagy and apoptosis. Additionally, signaling associated with nutrient sensing molecules, such as mTOR, AMPK, $\mathrm{Ca}^{2+}$ and SIRT1 can provide an insight into the metabolic side, whether metabolism shifts towards catabolic, energy-yielding processes or conserves energy, for example. The change in redox environment inside the cell would be a useful indicator to measure and would most likely support the theory that hormesis is a phenomenon based on compound-specific cellular effects.

Besides expanding the in-depth study of resveratrol, the general experimental concepts can easily be adapted to other substances, such as sulforaphane (see Appendix A). 


\section{Appendix A - Hormetic Behavior of Sulforaphane}

In addition to the compounds covered in the main text, sulforaphane was also screened for its hormetic behavior in the same cell model (HepG2).

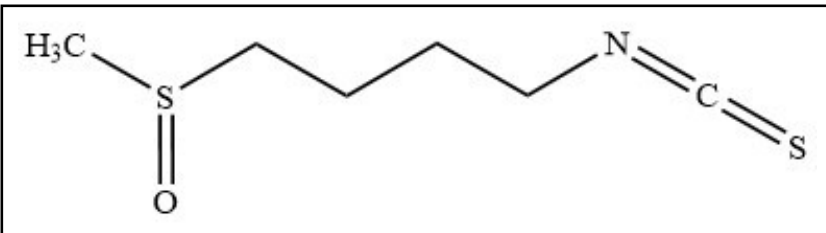

Figure A-1| Chemical Structure: Sulforaphane.

Over the past few years, sulforaphane has received a decent amount of scientific attention. The compound is an isothiocyanate and a product of an enzymatic hydrolysis of glucoraphanin, a substance commonly found in cruciform vegetables, the most recognized being broccoli. ${ }^{123-125}$ The enzyme (myrosinase) responsible for the release of sulforaphane is found right in the vegetable itself, but can also be found in human colon microbiota. Among a plethora of beneficial effects, it has been found to increase cell proliferation and angiogenesis, ${ }^{126}$ for example, and to have antioxidant and anti-inflammatory traits while displaying the characteristic biphasic effects of a hormetin: Cytoprotective and proliferative effects of sulforaphane have been ascribed to concentration levels below $10 \mu \mathrm{M}$ for several cell lines, including HepG2;118,126 higher levels though appear to decrease cell proliferation and induce apoptosis. ${ }^{118,127}$ Park et al. (2007) found an increase in pro-apoptotic Bax expression and a simultaneous decrease in Bcl-2 and Bcl- $\mathrm{X}_{\mathrm{L}}$ expression (anti-apoptotic factors) after HepG2 cells were exposed to sulforaphane, ${ }^{127}$ while Zou et al. (2017) attribute the onset of apoptosis to endoplasmic reticulum stress as they observed increased expression of Bip, Bid, XBP-1, CHOP, as well as caspase-12. ${ }^{128}$ The compounds antioxidant effect stems from the release of nuclear factor erythroid 2-related factor 2 (Nrf2) from the Keap1/Cul3/Rbx1/E3 complex ${ }^{*}$ upon binding of sulforaphane. ${ }^{123,126}$ Liberated Nrf2 induces expression of superoxide dismutase 1 (SOD1) and catalase ${ }^{129}$ in the nucleus, two major antioxidant enzymes. A wide range of scientific publication suggests that sulforaphane also increases phase II detoxification, especially with respect to carcinogens, ${ }^{130}$ through an increase in glutathione

\footnotetext{
${ }^{*}$ A complex formed by the noncovalent association of these four peptides: Kelch-like ECH-associated protein 1 (Keap1), Cullin 3 (Cul3), ring box 1 (Rbx1), and ubiquitin ligase E3 (E3). It serves as a redox sensing formation in the cytosol that binds Nrf2 under low oxidative cellular conditions. ${ }^{123}$
} 
$\mathrm{S}$ - transferase (GST), glutathione levels in general, thioredoxins, as well as quinone reductase, ${ }^{118,130-132}$ and reduces phase I metabolism, ${ }^{123,133}$ which can decrease a xenobiotics harmful potential.

\section{Effects on Metabolic Activity}

\section{Materials and Methods}

HepG2 cells were exposed to sulforaphane in varying concentrations $(0.01-500 \mu \mathrm{M})$ for 24 hours. Sulforaphane was acquired from Cayman Chemical Company. HepG2 (human hepatocellular carcinoma-derived) cells were cultured in Gibco ${ }^{\circledR}$ RPMI-1640 Medium without L-glutamine, supplemented with 5\% FBS, $2 \%$ penicillin and streptomycin, and $1 \% \mathrm{~L}$-glutamine, and maintained at $37^{\circ} \mathrm{C}$ in humidified, $5 \% \mathrm{CO}_{2}$ atmosphere. Before lifting, cells were washed twice with cold phosphate buffered saline. A stock solution of $50 \mathrm{mM}$ was prepared in DMSO. 100X dosing solutions were freshly mixed by serial dilution of the stock solution in DMSO. These were subsequently diluted 100-fold in culture media. The dosing solutions had a final DMSO concentration of $1 \%$. Cells were plated in a clear 96 well plate at a density of $60 \times 10^{3}$ cells/well in $100 \mu \mathrm{L}$ media and allowed to reattach for 24 hours. At this point, spent media was removed and $100 \mathrm{uL}$ fresh media supplied, which contained the respective concentration of sulforaphane.

The MTT reagent was prepared by dissolving 3,[4,5-dimethylthiazol-2-yl]-2,5-diphenyltetrazolium bromide in PBS to a concentration of $5 \mathrm{mg} / \mathrm{mL}$. The detergent was a solution of $10 \%$ SDS in DMSO containing 0.6\% glacial acetic acid. Briefly, after 24-hour exposure, $20 \mu \mathrm{L}$ of MTT reagent were added to each well. After 6 hours of incubation at $37^{\circ} \mathrm{C}, 100 \mu \mathrm{L} /$ well were dispensed and the plates allowed to rest for 5 minutes before they were shaken on an orbital shaker at $500 \mathrm{rpm}$ for 5 minutes. Absorbance was measured immediately after at $570 \mathrm{~nm}$ wavelength on a Fluostar Optima (BGM Labtech, Germany). Controls for this assay included untreated 1\% DMSO vehicle controls, as well as blank controls without cells at each concentration for background absorbance, since sulforaphane showed an increased absorbance with increased concentration, especially upon addition of the MTT reagent. 


\section{Results and Conclusion}

After 24 hours of exposure to sulforaphane $(0.01-500 \mu \mathrm{M})$, a significant increase in metabolic activity is seen at $5 \mu \mathrm{M}$ and $10 \mu \mathrm{M}$ compared to the untreated control (Figure A-1, Table A-1). A slight increase is noticeable, although not statistically significant, starting from $0.1 \mu \mathrm{M}$ and steadily rising to $5 \mu \mathrm{M}$. By that point, activity had increased by $53 \%$ in the mean. After that, the effect receded: $10 \mu \mathrm{M}$ still result in a $38 \%$ higher-than-control activity, $25 \mu \mathrm{M}$ tends to be less than $20 \%$ higher. The response to $50 \mu \mathrm{M}$ changed significantly compared to $25 \mu \mathrm{M}$, where metabolic activity already decreased down to $70 \%$ of the control value. Half of the metabolic activity was lost at 70 to $100 \mu \mathrm{M}$. Virtually no metabolic activity (3\%) was observed when cells were treated with $200 \mu \mathrm{M}$ of sulforaphane, or more.

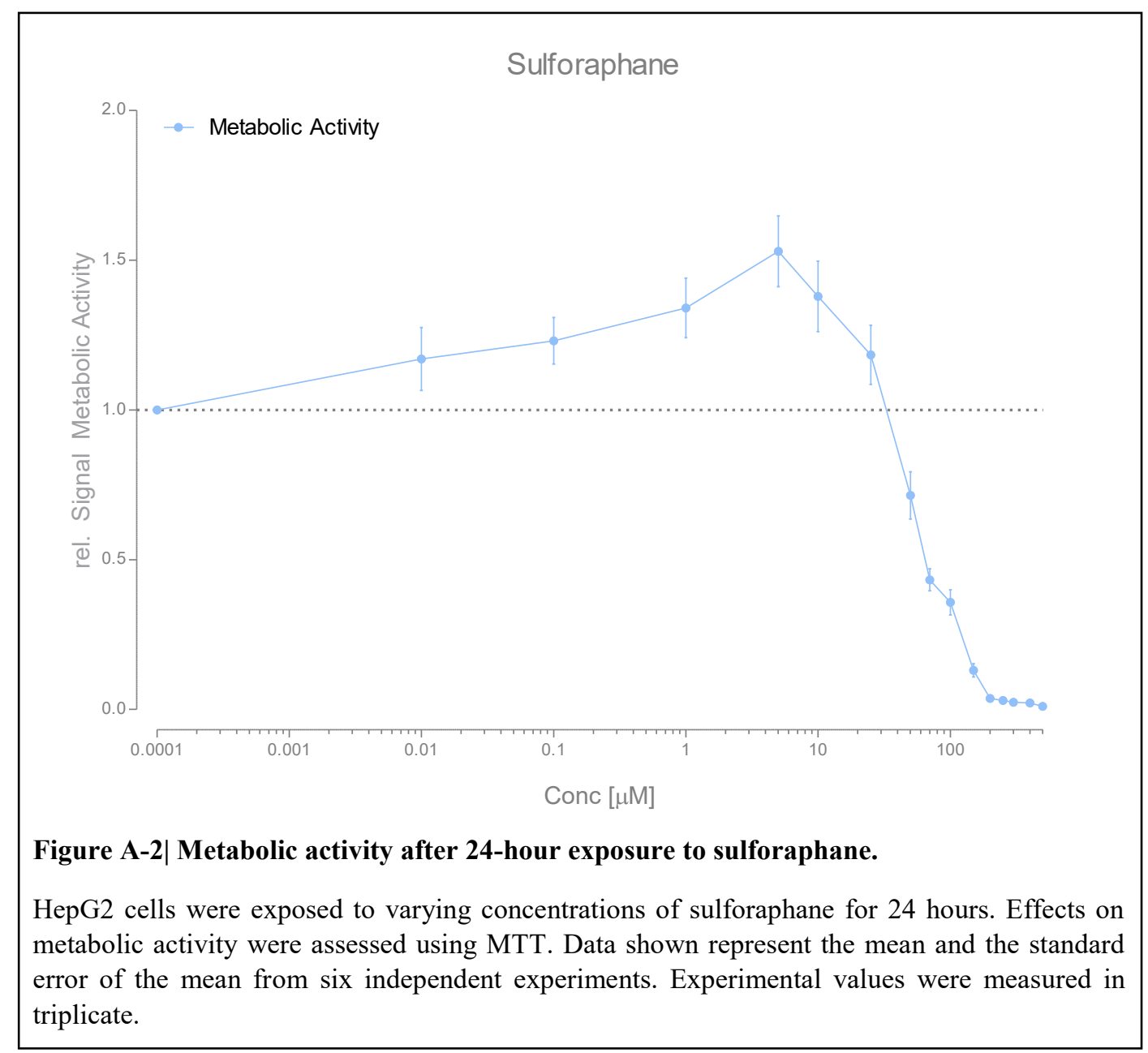


Table A-1| Summary of statistically significant changes in metabolic activity by sulforaphane concentration compared to untreated vehicle controls and previous concentrations.

\begin{tabular}{|c|c|c|c|c|}
\hline & \multicolumn{2}{|c|}{ Compared to Untreated Vehicle Control } & \multicolumn{2}{|c|}{ Compared to Previous Concentration } \\
\hline & Concentration $[\mu \mathrm{M}]$ & $\begin{array}{c}* \mathrm{p} \leq 0.05 \\
* * \mathrm{p} \leq 0.01 \\
* * * \mathrm{p} \leq 0.001\end{array}$ & Concentration $[\mu \mathrm{M}]$ & $\begin{aligned}{ }^{\#} \mathrm{p} \leq 0.05 \\
{ }^{\# \#} \mathrm{p} \leq 0.01 \\
{ }^{\# \#} \mathrm{p} \leq 0.001\end{aligned}$ \\
\hline \multirow{3}{*}{ Metabolic Activity } & 5 & $* * *$ & 50 & \#\#\# \\
\hline & 10 & $*$ & & \\
\hline & $70-500$ & $* * *$ & & \\
\hline
\end{tabular}

These results confirm previously reported observations ${ }^{119,128,130,134}$ and recommend sulforaphane as a prime subject for further investigation in plasma membrane integrity measurements and realtime experiments. However, data shown and discussed in Appendix B draws doubt on the just presented data and the reliability of the performed experiments under the chosen experimental conditions. 


\section{Appendix B - Impact of Cell Population and Instrumentation}

The data presented in the main text was uniformly acquired in the same laboratory, using the same cell culture reagents, the same equipment, and instrumentation. However, comparative data for epigallocatechin gallate, quercetin, and resveratrol was also acquired in a laboratory at the Fulda University of Applied Sciences with a different population of HepG2 cells, different reagents, and instrumentation. Instrument bias and speculations on the source of cell population variability have been discussed in literature before, ${ }^{135-137}$ the following is a comparison of the data gathered in both laboratories, which impressively shows the impact of cell population and instrumentation on research outcomes.

\section{Methods and Materials}

Materials and methodology are described in detail in the main text for the data labeled "West Virginia University". Data labeled with "Fulda U.o.A.Science" was acquired as presented below:

\section{Materials}

All materials were acquired from VWR, unless otherwise specified. Quercetin, (-)epigallocatechin gallate, and trans-resveratrol, were obtained from Cayman Chemical Company.

\section{Cell Culture}

HepG2 (human hepatocellular carcinoma-derived) cells were cultured in Gibco® RPMI-1640 Medium without L-glutamine, supplemented with 5\% FBS, 2\% penicillin and streptomycin, and $1 \%$ L-glutamine, and maintained at $37{ }^{\circ} \mathrm{C}$ in humidified, $5 \% \mathrm{CO}_{2}$ atmosphere. Before lifting, cells were washed twice with cold phosphate buffered saline.

MTT Assay

Cell viability assays were performed using these solutions: The MTT reagent was prepared by dissolving 3,[4,5-dimethylthiazol-2-yl]-2,5-diphenyl-tetrazolium bromide in PBS to a concentration of $5 \mathrm{mg} / \mathrm{mL}$. The detergent was a solution of $10 \%$ SDS in DMSO containing $0.6 \%$ concentrated acetic acid. Briefly, after 24-hour exposure, $20 \mu \mathrm{L}$ of MTT reagent were added to 
each well. After 6 hours of incubation at $37^{\circ} \mathrm{C}, 100 \mu \mathrm{L} /$ well were dispensed and the plates allowed to rest for 5 minutes before they were shaken on an orbital shaker at $500 \mathrm{rpm}$ for 5 minutes. Absorbance was measured immediately after at $570 \mathrm{~nm}$ wavelength on a Fluostar Optima (BGM Labtech, Germany). All other aspects were similar to the procedures laid out in the main text.

\section{Results and Discussion}
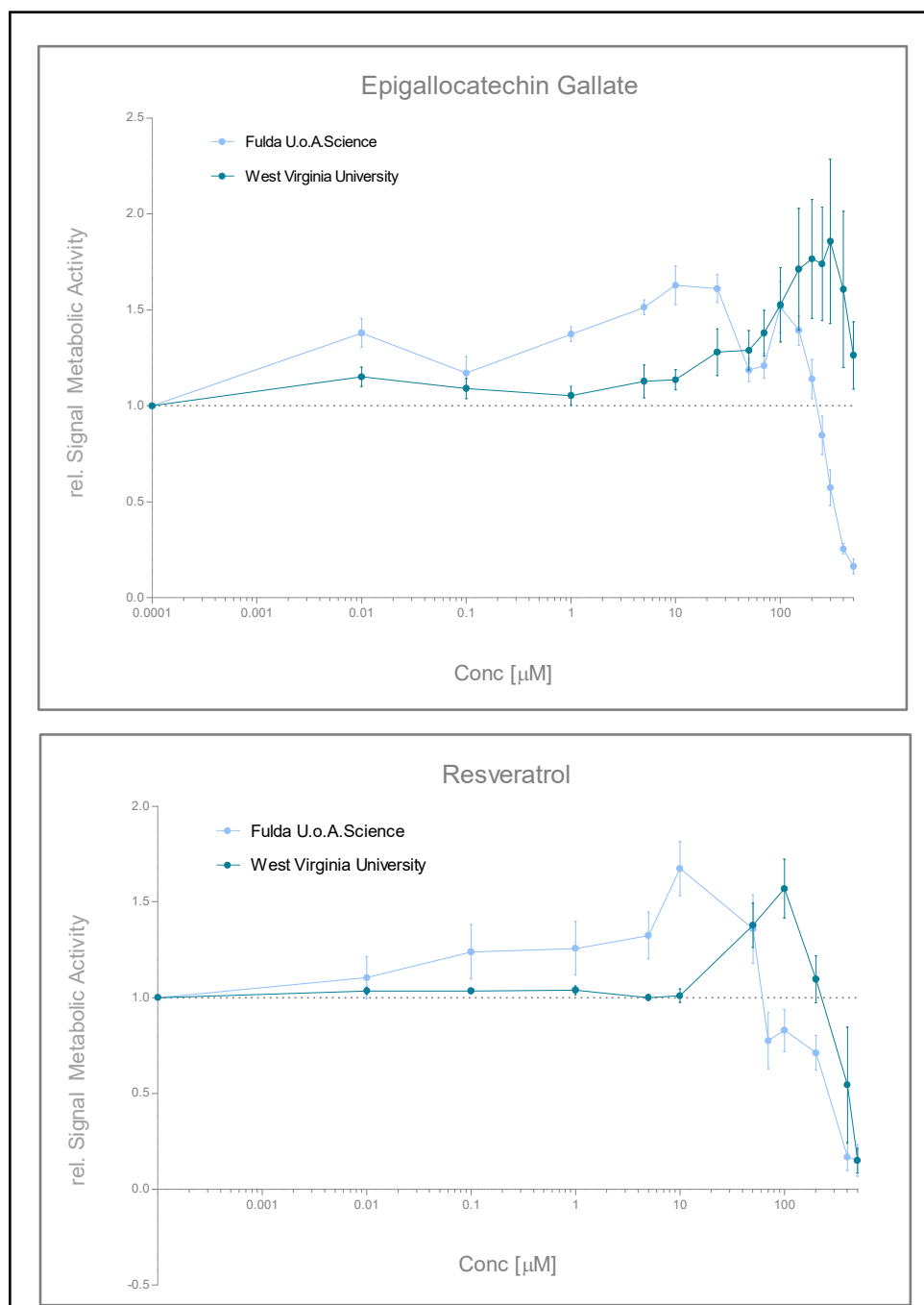

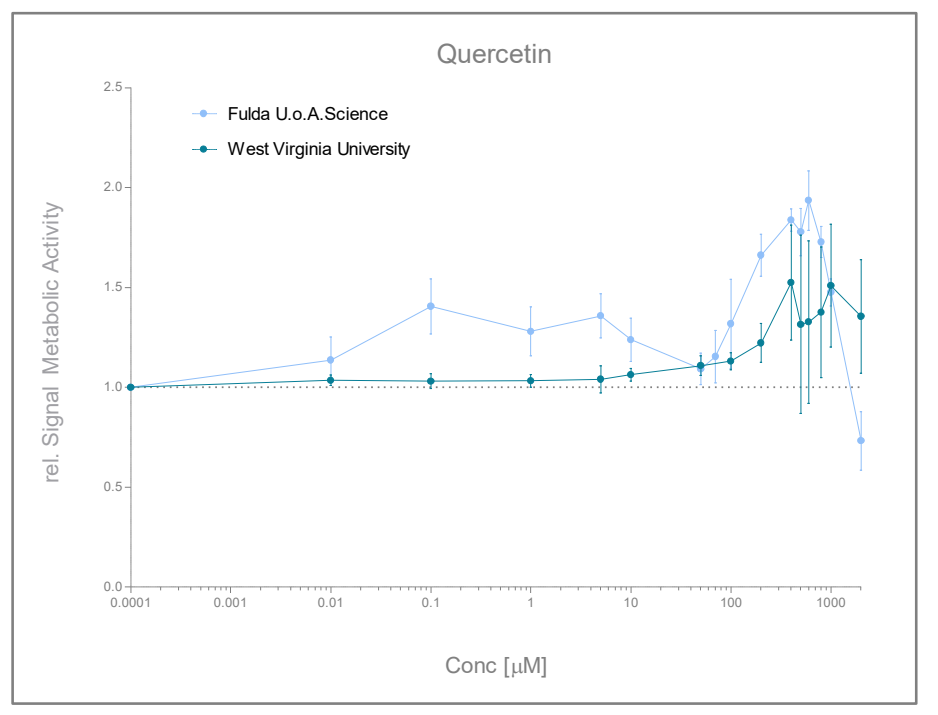

Figure B-1| Comparison of metabolic activity data after exposure of HepG2 cells to epigallocatechin gallate, quercetin, and resveratrol from two different laboratories with varying cell population, instrumentation, and assay reagents.

HepG2 cells were exposed to varying concentrations of epigallocatechin gallate (top left), quercetin (top right), and resveratrol (bottom) for 24 hours. Effects on metabolic activity were assessed using MTT. Data shown represent the mean and the standard error of the mean from six independent experiments for the Fulda U.o.A.Science dataset and four independent experiments for the West Virginia University dataset. Experimental values were measured in triplicate. 
Table B-1| Comparative summary of statistically significant changes in metabolic activity by compound concentration compared to untreated vehicle controls and previous concentrations.

\begin{tabular}{|c|c|c|c|c|}
\hline & \multicolumn{2}{|c|}{ Compared to Untreated Vehicle Control } & \multicolumn{2}{|c|}{ Compared to Previous Concentration } \\
\hline Metabolic Activity & Concentration $[\mu \mathrm{M}]$ & $\begin{array}{c}* \mathrm{p} \leq 0.05 \\
* * \mathrm{p} \leq 0.01 \\
* * * \mathrm{p} \leq 0.001\end{array}$ & Concentration $[\mu \mathrm{M}]$ & $\begin{array}{c}{ }^{\#} \mathrm{p} \leq 0.05 \\
{ }^{\#} \mathrm{p} \leq 0.01 \\
\#^{\# \#} \mathrm{p} \leq 0.001\end{array}$ \\
\hline
\end{tabular}

Epigallocatechin Gallate

\begin{tabular}{|c|c|c|c|}
\hline West Virginia University & \multicolumn{2}{|c|}{ No statistically significant changes } & \multicolumn{2}{|c|}{ No statistically significant changes } \\
\hline \hline \multirow{3}{*}{ Fulda U.o.A.Science } & 5 & $* *$ & \multicolumn{2}{|c|}{50} \\
\cline { 2 - 4 } & $10 \& 25$ & $* * *$ & \\
\cline { 2 - 4 } & 100 & $* *$ & \\
\cline { 2 - 4 } & 300 & $* * *$ & \\
\cline { 2 - 4 } & $400 \& 500$ & & \\
\hline
\end{tabular}

Quercetin

\begin{tabular}{|c|c|c|c|}
\hline West Virginia University & \multicolumn{2}{|c|}{ No statistically significant changes } & \multicolumn{2}{|c|}{ No statistically significant changes } \\
\hline \hline \multirow{3}{*}{ Fulda U.o.A.Science } & $200 \& 400$ & $*$ & \multicolumn{2}{|c|}{2000} \\
\cline { 2 - 4 } & 500 & $* *$ & \\
\cline { 2 - 4 } & 600 & $* * *$ & \\
\cline { 2 - 4 } & 800 & $* *$ & \\
\hline
\end{tabular}

Resveratrol

\begin{tabular}{|c|c|c|c|}
\hline West Virginia University & 500 & $* * *$ & No statistically significant changes \\
\hline \hline \multirow{2}{*}{ Fulda U.o.A.Science } & $10 \& 400$ & $* *$ & No statistically significant changes \\
\cline { 2 - 4 } & 500 & $* * *$ & \\
\hline
\end{tabular}

Metabolic activity in response to a 24-hour exposure of three compounds (epigallocatechin gallate, quercetin, and resveratrol) was investigated in two laboratories, one at West Virginia University, the other one at Fulda University of Applied Science (Fulda U.o.A.Science). Cell culture stock and reagents, assay conditions, and instrumentation varied between the two laboratories, which was clearly observable in the acquired data.

In the case of epigallocatechin gallate, the mean values from Fulda describe a very interesting behavior: Metabolic activity did not change significantly up to $5 \mu \mathrm{M}$ compared to vehicle control, but at $5 \mu \mathrm{M}$ activity increased by $51 \%$ in the mean and even by $63 \%$ and $61 \%$ at $10 \mu \mathrm{M}$ and $25 \mu \mathrm{M}$, respectively. $50 \mu \mathrm{M}$ did not change the response significantly compared to vehicle controls, but compared to the previous concentration of $25 \mu \mathrm{M}$ the signal decreased markedly. $100 \mu \mathrm{M}$ again boosted metabolic activity 53\% above the control level. Concentrations higher than $100 \mu \mathrm{M}$ then continuously impeded metabolic response, for example down to about $50 \%$ of the control value from $300 \mu \mathrm{M}$ exposure and less than $20 \%$ for the highest exposure of $500 \mu \mathrm{M}$. 
The cellular response was not reproducible in the American laboratory. High variability in the independent experiments drove the standard error of the mean, therefore no statistically significant changes in metabolic activity were found. However, a slight trend of increased metabolic activity past $100 \mu \mathrm{M}$ was observed, although the signal did not decrease below control values even at the highest dose.

Similarly, trends from resveratrol exposure shifted and were not reproducible. While the data from Fulda point to a statistically significant peak increase in metabolic activity at $10 \mu \mathrm{M}(67 \%)$ and a decrease of activity starting at $70 \mu \mathrm{M}$, data from West Virginia University does not show a significantly increased response until $50 \mu \mathrm{M}$ and $100 \mu \mathrm{M}$ (38\% and $57 \%$, respectively) and a decreased activity starting between 200 and $400 \mu \mathrm{M}$. Only $50 \mu \mathrm{M}$ and $500 \mu \mathrm{M}$ evoked a comparable cellular metabolic activity.

The shift in concentration response was somewhat less pronounced when cells were exposed to Quercetin. Concentrations between $200 \mu \mathrm{M}$ and $1000 \mu \mathrm{M}$ increased the metabolic activity by $50 \%$ to almost $100 \%$ of the vehicle control values. Lower concentrations in the range of $0.1 \mu \mathrm{M}$ to $10 \mu \mathrm{M}$ also strengthened metabolism noticeably up to $40 \%$, but not statistically significantly. Compared to that, no statistically significant changes were observed in the experiments from West Virginia University, especially at higher concentrations, due to exceptionally large standard errors. A small trend of increased metabolic activity could be inferred at $200 \mu \mathrm{M}$. Smaller doses from $0.01 \mu \mathrm{M}$ to $10 \mu \mathrm{M}$ demonstrated no noticeable difference.

The data provided is a prime example of the impact of instrumentation and reagent/procedure consistency on experimental outcome. There is no method to determine which laboratory results are closest to the actual cellular behavior, unless more independent trials are performed. Even then it is not guaranteed that the results will converge, as the genetic and behavioral variation between separate populations of the same cell line can be, as demonstrated, quite large. It would be interesting to see how large the difference in results would be with the same protocols, chemicals, and instrumentation to assess the true impact of cell population. Single cell measurements might be a better way to study the exact effects of hormetic compounds, since it has been shown before that actual signaling events can be significantly different from what cell population studies suggest. ${ }^{12}$ 


\section{BIBLIOGRAPHY}

1. Murugaiyah, V. \& Mattson, M. P. Neurohormetic phytochemicals : An evolutionarybioenergetic perspective. Neurochem. Int. 89, 271-280 (2015).

2. Naviaux, R. K. Metabolic features of the cell danger response. Mitochondrion 16, 7-17 (2014).

3. Vargas, A. J. \& Burd, R. Hormesis and synergy: Pathways and mechanisms of quercetin in cancer prevention and management. Nutr. Rev. 68, 418-428 (2010).

4. Blagosklonny, M. V. Hormesis does not make sense except in the light of TOR-driven aging. Aging (Albany. NY). 3, 1051-1062 (2011).

5. Brasili, E. \& Filho, V. C. Metabolomics of cancer cell cultures to assess the effects of dietary phytochemicals. Crit. Rev. Food Sci. Nutr. 57, 1328 (2017).

6. Son, T. G., Camandola, S. \& Mattson, M. P. Hormetic Dietary Phytochemicals. Neuromolecular Med. 10, 236-246 (2008).

7. Le Bourg, É. Hormesis, aging and longevity. Biochim. Biophys. Acta - Gen. Subj. 1790, 1030-1039 (2009).

8. Calabrese, E. J. Hormesis: Changing view of the dose-response, a personal account of the history and current status. Mutat. Res. 511, 181-189 (2002).

9. Mattson, M. P. What doesn't kill you... Chemicals that plants make to ward off pests stimulate nerve cells in ways that may protect the brain against diseases such as Alzheimer's and Parkinson's. Sci. Am. 313, 41-45 (2015).

10. Rattan, S. I. S. Molecular Gerontology: From Homeodynamics to Hormesis. Curr. Pharm. Des. 20, (2014).

11. Kinoshita, A. \& Wanibuchi, H. Hormesis in carcinogenicity of non-genotoxic carcinogens. J. Toxicol. Pathol. 19, 111-122 (2006).

12. Purvis, J. E. \& Lahav, G. Encoding and decoding cellular information through signaling dynamics. Cell 152, 945-956 (2013).

13. JM Berg, JL Tymoczko \& L Stryer. Biochemistry (W H Freeman, 2002).

14. Kholodenko, B. Cell-signalling dynamics in time and space. Nat. Rev. Mol. Cell Biol. 7, 165-176 (2006).

15. Tait, S. W. G. \& Green, D. R. Mitochondria and cell signalling. J. Cell Sci. 125, 807-15 (2012).

16. Cheng, Z. \& Ristow, M. Mitochondria and metabolic homeostasis. Antioxid. Redox Signal. 19, 240-2 (2013).

17. Ji, A.-R. et al. Reactive oxygen species enhance differentiation of human embryonic stem cells into mesendodermal lineage. Exp. Mol. Med. 42, 175-186 (2010). 
18. Sauer, H., Wartenberg, M. \& Hescheler, J. Reactive Oxygen Species as Intracellular Messengers During Cell Growth and Differentiation. Cell. Physiol. Biochem. 11, 173-186 (2001).

19. Linley, J. E. et al. Reactive oxygen species are second messengers of neurokinin signaling in peripheral sensory neurons. Proc. Natl. Acad. Sci. U. S. A. 109, E1578-86 (2012).

20. Housden, B. E. \& Perrimon, N. Spatial and temporal organization of signaling pathways. Trends Biochem. Sci. 39, 457-464 (2014).

21. Kholodenko, B. N. Spatially distributed cell signalling. FEBS Lett. 583, 4006-4012 (2009).

22. Ferri, K. F. \& Kroemer, G. Organelle-specific initiation of cell death pathways. Nat. Cell Biol. 3, E255-E263 (2001).

23. Voet, D. \& Voet, J. G. Biochemistry. (John Wiley \& Sons, Inc., 2011).

24. OpenStax College. Biology. (OpenStax College, 2013).

25. Lodish, H. et al. Molecular Cell Biology. (W. H. Freeman and Company, 2008).

26. Dashty, M. A quick look at biochemistry: Carbohydrate metabolism. Clin. Biochem. 46, 1339-1352 (2013).

27. Horton, H. R. Principles of biochemistry. (Pearson Education, 2002).

28. Sjulstok, E., Olsen, J. M. H. \& Solov'yov, I. A. Quantifying electron transfer reactions in biological systems: what interactions play the major role? Sci. Rep. 5, 18446 (2016).

29. Mansoorabadl, S. O., Thibodeaux, C. J. \& Liu, H. The Diverse Roles of Flavin Coenzymes - Nature's Most Versatile Thespians. J. Org. Chem. 72, 6329-6342 (2007).

30. Wang, L., Liu, W., Liu, Y., Wang, X. \& Zhao, Z. Orthogonal Redox Systems and their Potential Applications. Sci. Sin. Vitae 45, 969-975 (2015).

31. Belenky, P., Bogan, K. L. \& Brenner, C. NAD ${ }^{+}$metabolism in health and disease. Trends Biochem. Sci. 32, 12-19 (2007).

32. Pollak, N., Dölle, C. \& Ziegler, M. The power to reduce: pyridine nucleotides - small molecules with a multitude of functions. Biochem. J. 402, 205-218 (2007).

33. Cooper GM. The Cell: A Molecular Approach (Sinauer Associates, 2000).

34. Warburg, O., Posener, K. \& Negelein, E. Über den Stoffwechsel der Carcinomazelle. Biochem. Z. 152, 309-344 (1924).

35. Mulukutla, B. C., Khan, S., Lange, A. \& Hu, W.-S. Glucose metabolism in mammalian cell culture: new insights for tweaking vintage pathways TL - 28. Trends Biotechnol. 28, 476484 (2010).

36. Vander Heiden, M., Cantley, L. \& Thompson, C. Understanding the Warburg effect: The metabolic Requiremetns of cell proliferation. Science (80). 324, 1029-1033 (2009). 
37. Efeyan, A., Comb, W. C. \& Sabatini, D. M. Nutrient-sensing mechanisms and pathways. Nature 517, 302-310 (2015).

38. Kemp, B. E. et al. Dealing with energy demand: the AMP-activated protein kinase. Trends Biochem. Sci. 24, 22-25 (1999).

39. Lorendeau, D., Christen, S., Rinaldi, G. \& Fendt, S.-M. Metabolic control of signalling pathways and metabolic auto-regulation. Biol. Cell 107, 251-72 (2015).

40. Ruderman, N. B., Carling, D., Prentki, M. \& Cacicedo, J. M. AMPK, insulin resistance, and the metabolic syndrome. J. Clin. Invest. 123, 2764-2772 (2013).

41. Hardie, D. G. \& Ashford, M. L. J. AMPK: Regulating Energy Balance at the Cellular and Whole Body Levels. Physiology 29, 99-107 (2014).

42. Hardie, D. G. AMPK - Sensing energy while talking to other signaling pathways. Cell Metab. 20, 939-952 (2014).

43. Hardie, D. G., Scott, J. W., Pan, D. A. \& Hudson, E. R. Management of cellular energy by the AMP-activated protein kinase system. FEBS Lett. 546, 113-120 (2003).

44. Towler, M. C. \& Hardie, D. G. AMP-activated protein kinase in metabolic control and insulin signaling. Circ. Res. 100, 328-341 (2007).

45. Hardie, D. G., Schaffer, B. E. \& Brunet, A. AMPK: An Energy-Sensing Pathway with Multiple Inputs and Outputs. Trends Cell Biol. 26, 190-201 (2016).

46. Mihaylova, M. M. \& Shaw, R. J. The AMPK signalling pathway coordinates cell growth, autophagy and metabolism. Nat. Cell Biol. 13, 1016-1023 (2011).

47. Staples, J. F. \& Buck, L. T. Matching cellular metabolic supply and demand in energystressed animals. Comp. Biochem. Physiol. 153, 95-105 (2009).

48. Thorburn, A. Apoptosis and Autophagy: regulatory connections between two supposedly different processes. Apoptosis 13, 23-29 (2008).

49. Giansanti, V. \& Scovassi, A. I. Cell Death : A One-Way Journey to the Graveyard. Open Biol. J. 1, 27-34 (2008).

50. Renehan, A. G. What is apoptosis, and why is it important? Bmj 322, 1536-1538 (2001).

51. Czabotar, P. E., Lessene, G., Strasser, A. \& Adams, J. M. Control of apoptosis by the Bcl2 protein family: implications for physiology and therapy. Nat. Rev. Mol. Cell Biol. 15, 4963 (2014).

52. Rehm, M., Düßgmann, H. \& Prehn, J. H. M. Real-time single cell analysis of Smac/DIABLO release during apoptosis. J. Cell Biol. 162, 1031-1043 (2003).

53. Ouyang, L. et al. Programmed cell death pathways in cancer: A review of apoptosis, autophagy and programmed necrosis. Cell Prolif. 45, 487-498 (2012).

54. Martins, I., Galluzzi, L. \& Kroemer, G. Hormesis, cell death and aging. Aging (Albany. NY). 3, 821-828 (2011). 
55. Fan, Y.-J. \& Zong, W.-X. The cellular decision between apoptosis and autophagy. Chin. J. Cancer 32, 121-129 (2013).

56. Sack, M. N. Regulation of autophagy and mitophagy by nutrient availability and acetylation. Biochim. Biophys. Acta 1841, 525-534 (2014).

57. Mizushima, N. Autophagy : process and function. Genes Dev. 21, 2861-2873 (2007).

58. Naponelli, V., Modernelli, A., Bettuzzi, S. \& Rizzi, F. Roles of autophagy induced by natural compounds in prostate cancer. Biomed Res. Int. (2015).

59. Tooze, S. A. \& Yoshimori, T. The origin of the autophagosomal membrane. Nat. Cell Biol. 12, 831-835 (2010).

60. Roberts, D. J. \& Miyamoto, S. Hexokinase II integrates energy metabolism and cellular protection: Akting on mitochondria and TORCing to autophagy. Cell Death Differ. 22, 364364 (2015).

61. Klionsky, D. J. et al. Guidelines for the use and interpretation of assays for monitoring autophagy. Autophagy 8, 445-544 (2012).

62. Neto, C. C. Cranberry and its phytochemicals: a review of in vitro anticancer studies. $J$. Nutr. 137, 186S-193S (2007).

63. Miller, P. E. \& Snyder, D. C. Phytochemicals and Cancer Risk. Nutr. Clin. Pract. 27, 599 612 (2012).

64. Karve, T. M. \& Cheema, A. K. Small Changes Huge Impact: The Role of Protein Posttranslational Modifications in Cellular Homeostasis and Disease. J. Amino Acids 2011, $1-13$ (2011).

65. Surh, Y.-J. Cancer chemoprevention with dietary phytochemicals. Nat. Rev. Cancer 3, 768780 (2003).

66. Pietsch, K. et al. Hormetins, antioxidants and prooxidants: Defining quercetin-, caffeic acidand rosmarinic acid-mediated life extension in C. elegans. Biogerontology 12, 329-347 (2011).

67. Ramos, A. A., Lima, C. F., Pereira, M. L., Fernandes-Ferreira, M. \& Pereira-Wilson, C. Antigenotoxic effects of quercetin, rutin and ursolic acid on HepG2 cells: Evaluation by the comet assay. Toxicol. Lett. 177, 66-73 (2008).

68. Van Der Woude, H. et al. Biphasic modulation of cell proliferation by quercetin at concentrations physiologically relevant in humans. Cancer Lett. 200, $41-47$ (2003).

69. Kim, G. N. \& Jang, H. D. Protective mechanism of quercetin and rutin using glutathione metabolism on $\mathrm{H}_{2} \mathrm{O}_{2}$-induced oxidative stress in HepG2 cells. Ann. N. Y. Acad. Sci. 1171, 530-537 (2009).

70. Min, K. \& Ebeler, S. E. Quercetin inhibits hydrogen peroxide-induced DNA damage and enhances DNA repair in Caco-2 cells. Food Chem. Toxicol. 47, 2716-2722 (2009). 
71. Weng, C. J., Chen, M. J., Yeh, C. T. \& Yen, G. C. Hepatoprotection of quercetin against oxidative stress by induction of metallothionein expression through activating MAPK and PI3K pathways and enhancing Nrf2 DNA-binding activity. N. Biotechnol. 28, 767-777 (2011).

72. Tan, J., Wang, B. \& Zhu, L. Regulation of survivin and Bcl-2 in HepG2 cell apoptosis induced by quercetin. Chem. Biodivers. 6, 1101-1110 (2009).

73. Jimenez-Lopez, J. M. \& Cederbaum, A. I. Green tea polyphenol epigallocatechin-3-gallate protects HepG2 cells against CYP2E1-dependent toxicity. Free Radic. Biol. Med. 36, 359370 (2004).

74. Park, H. J. et al. Epigallocatechin gallate reduces hypoxia-induced apoptosis in human hepatoma cells. Life Sci. 78, 2826-32 (2006).

75. Zhou, J. et al. Epigallocatechin-3-Gallate (EGCG), a Green Tea Polyphenol, Stimulates Hepatic Autophagy and Lipid Clearance. PLoS One 9, (2014).

76. Shen, X. et al. Epigallocatechin-3-gallate inhibits cell growth, induces apoptosis and causes S phase arrest in hepatocellular carcinoma by suppressing the AKT pathway. Int. J. Oncol. 44, 791-796 (2014).

77. Roberto, M., Oliveira, D., Fazel, S., Daglia, M. \& Rastrelli, L. Epigallocatechin gallate and mitochondria - A story of life and death. Pharmacol. Res. 104, 70-85 (2016).

78. Rainey, N., Motte, L., Aggarwal, B. B. \& Petit, P. X. Curcumin hormesis mediates a crosstalk between autophagy and cell death. Cell Death Dis. 6, e2003 (2015).

79. Wang, M. et al. Curcumin induced HepG2 cell apoptosis-associated mitochondrial membrane potential and intracellular free $\mathrm{Ca}^{+}$concentration. Eur. J. Pharmacol. 650, 4147 (2011).

80. Moustapha, A. et al. Curcumin induces crosstalk between autophagy and apoptosis mediated by calcium release from the endoplasmic reticulum, lysosomal destabilization and mitochondrial events. Cell Death Discov. 1, 15017 (2015).

81. Qian, H., Yang, Y. \& Wang, X. Curcumin enhanced adriamycin-induced human liverderived Hepatoma $\mathrm{G} 2$ cell death through activation of mitochondria-mediated apoptosis and autophagy. Eur. J. Pharm. Sci. 43, 125-131 (2011).

82. Das, L. \& Vinayak, M. Long term effect of curcumin in restoration of tumour suppressor p53 and phase-II antioxidant enzymes via activation of $\mathrm{Nrf} 2$ signalling and modulation of inflammation in prevention of cancer. PLoS One 10, 1-22 (2015).

83. Marcsek, Z. L., Kocsis, Z., Szende, B. \& Tompa, A. Effect of formaldehyde and resveratrol on the viability of Vero, HepG2 and MCF-7 cells. Cell Biol. Int. 31, 1214-1219 (2007).

84. Plauth, A. et al. Hormetic shifting of redox environment by pro-oxidative resveratrol protects cells against stress. Free Radic. Biol. Med. 99, 608-622 (2016).

85. Calabrese, E. J., Mattson, M. P. \& Calabrese, V. Dose response biology: the case of resveratrol. Hum. Exp. Toxicol. 29, 1034-1037 (2010). 
86. Juhasz, B., Mukherjee, S. \& Das, D. K. Hormetic response of resveratrol against cardioprotection. Exp. Clin. Cardiol. 15, 2-6 (2010).

87. Delmas, D., Jannin, B., Cherkaoui Malki, M. \& Latruffe, N. Inhibitory effect of resveratrol on the proliferation of human and rat hepatic derived cell lines. Oncol. Rep. 7, 847-852 (2000).

88. Takashina, M. et al. Different effect of resveratrol to induction of apoptosis depending on the type of human cancer cells. Int. J. Oncol. 50, 787-797 (2017).

89. Calabrese, E. J., Mattson, M. P. \& Calabrese, V. Resveratrol commonly displays hormesis: Occurrence and biomedical significance. Hum. Exp. Toxicol. 29, 980-1015 (2010).

90. Ou, X., Chen, Y., Cheng, X., Zhang, X. \& He, Q. Potentiation of resveratrol-induced apoptosis by matrine in human hepatoma HepG2 cells. Oncol. Rep. 32, 2803-2809 (2014).

91. Lüer, S. C., Goette, J., Troller, R. \& Aebi, C. Synthetic versus natural curcumin: bioequivalence in an in vitro oral mucositis model. BMC Complement. Altern. Med. 14, 53 (2014).

92. Anisimova, N. Y. et al. Trans-, cis-, and dihydro-resveratrol: a comparative study. Chem. Cent. J. 5, 88 (2011).

93. Liu, Y., Peterson, D. A., Kimura, H. \& Schubert, D. Mechanism of Cellular 3-(4,5Dimethylthiazol-2-yl)-2,5-Diphenyltetrazolium Bromide (MTT) Reduction. J. Neurochem. 69, 581-593 (1997).

94. Sittampalam, G. S. et al. Assay Guidance Manual. Assay Guidance Manual (Eli Lilly \& Company and the national Center for Advancing Translational Sciences, 2017).

95. Schmitz, S. Der Experimentator Zellkultur. (Spektrum Akademischer Verlag, 2011).

96. Stoddart, M. J. Mammalian Cell Viability 740, 1-6 (2011).

97. Haugland, R. P., MacCoubry, I. C. \& Moore, P. L. Dual-fluorescence cell viability assay using ethidium homodimer and calcein AM. (1991).

98. Kricka, L. J. \& Fortina, P. Analytical ancestry: "firsts" in fluorescent labeling of nucleosides, nucleotides, and nucleic acids. Clin. Chem. 55, 670-683 (2009).

99. Tajiri, N. et al. A Nuclear Attack on Traumatic Brain Injury: Sequestration of Cell Death in the Nucleus. CNS Neurosci. Ther. 22, 306-315 (2016).

100. Zapf, M. A. C. et al. Green tea component epigallocatechin-3-gallate decreases expression of osteopontin via a decrease in mRNA half-life in cell lines of metastatic hepatocellular carcinoma. Surgery 158, 1039-1048 (2015).

101. Waheed Roomi, M., Roomi, N. W., Kalinovsky, T., Niedzwiecki, A. \& Rath, M. Micronutrient synergy in the fight against hepatocellular carcinoma. Cancers (Basel). 4, 323-339 (2012).

102. Calabrese, V. et al. The Hormetic Role of Dietary Antioxidants in Free Radical-Related Diseases. Curr. Pharm. Des. 16, 877-883 (2010). 
103. Ye, Q. et al. Epigallocatechin-3-gallate suppresses 1-methyl-4-phenyl-pyridine-induced oxidative stress in PC12 cells via the SIRT1/PGC-1 $\alpha$ signaling pathway. BMC Complement. Altern. Med. 12, 1042 (2012).

104. Tanigawa, S., Fujii, M. \& Hou, D.-X. Stabilization of p53 is involved in quercetin-induced cell cycle arrest and apoptosis in HepG2 cells. Biosci. Biotechnol. Biochem. 72, 797-804 (2008).

105. Kunwar, A., Barik, A. \& Priyadarsini, K. I. Absorption and Fluorescence Studies of Curcumin Bound To Liposome and Living Cells. 2Barc Newsl. 213-219 (2007).

106. Wang, Q., Wang, D. \& Li, D. Curcumin as fluorescent probe for directly monitoring in vitro uptake of curcumin combined paclitaxel loaded PLA-TPGS nanoparticles. Adv. Nat. Sci. Nanosci. Nanotechnol. 7, 0 (2016).

107. Chien, S.-Y. et al. Quercetin-induced apoptosis acts through mitochondrial- and caspase-3dependent pathways in human breast cancer MDA-MB-231 cells. Hum. Exp. Toxicol. 28, 493-503 (2009).

108. Schrauwen, P. \& Timmers, S. Can resveratrol help to maintain metabolic health? Proc. Nutr. Soc. 73, 271-7 (2014).

109. Albani, D. et al. The SIRT1 activator resveratrol protects SK-N-BE cells from oxidative stress and against toxicity caused by alpha-synuclein or amyloid-beta (1-42) peptide. $J$. Neurochem. 110, 1445-1456 (2009).

110. Peltz, L. et al. Resveratrol exerts dosage and duration dependent effect on human mesenchymal stem cell development. PLoS One 7, (2012).

111. Martins, L. A. M. et al. Resveratrol Induces Pro-oxidant Effects and Time-Dependent Resistance to Cytotoxicity in Activated Hepatic Stellate Cells. Cell Biochem. Biophys. 68, 247-257 (2014).

112. Vrana, J. A., Currie, H. N., Han, A. A. \& Boyd, J. Forecasting Cell Death Dose-Response from Early Signal Transduction Responses In Vitro. Toxicol. Sci. 140, 338-351 (2014).

113. Hata, A. N. et al. Tumore Cells can follow distinct evolutionary path to become resistant to epidermal growth factor receptor inhibition. Nat Med 22, 262-269 (2016).

114. Brandenburg, K. S. et al. Inhibition of Pseudomonas aeruginosa biofilm formation on wound dressings. Wound Repair Regen 23, 842-854 (2015).

115. Valley, M. P. et al. A bioluminescent assay for measuring glucose uptake. Anal. Biochem. 505, 43-50 (2016).

116. Duellman, S. J. et al. Bioluminescent, Nonlytic, Real-Time Cell Viability Assay and Use in Inhibitor Screening. Assay Drug Dev. Technol.(2015).

117. Promega Corporation. RealTime-Glo ${ }^{\mathrm{TM}}$ MT Cell Viability Assay Technical Manual. \#TM431

118. Gan, N. et al. Sulforaphane protects Microcystin-LR-induced toxicity through activation of the Nrf2-mediated defensive response. Toxicol. Appl. Pharmacol. 247, 129-137 (2010). 
119. Kim, B. R. et al. Effects of Glutathione on Antioxidant Response Element-Mediated Gene Expression and Apoptosis Elicited by Sulforaphane. Cancer Res. 63, 7520-7525 (2003).

120. Tello Velasquez, J. et al. Low-dose curcumin stimulates proliferation, migration and phagocytic activity of olfactory ensheathing cells. PLoS One 9, e111787 (2014).

121. Promega. CellTiter-Glo 2.0 Assay Technical Manual.

122. Birchler, A. et al. Seamless Combination of Fluorescence-Activated Cell Sorting and Hanging-Drop Networks for Individual Handling and Culturing of Stem Cells and Microtissue Spheroids. Anal. Chem. (2016).

123. Glade, M. J. \& Meguid, M. M. A Glance at... Broccoli, glucoraphanin, and sulforaphane. Nutrition 31, 1175-1178 (2015).

124. Robbins, M. G. et al. Induction of detoxification enzymes by feeding unblanched brussels sprouts containing active myrosinase to mice for 2 wk. J. Food Sci. 75, 190-199 (2010).

125. Haack, M. et al. Breakdown products of neoglucobrassicin inhibit activation of Nrf2 target genes mediated by myrosinase-derived glucoraphanin hydrolysis products. Biol. Chem. 391, 1281-1293 (2010).

126. Bao, Y., Wang, W., Zhou, Z. \& Sun, C. Benefits and risks of the hormetic effects of dietary isothiocyanates on cancer prevention. PLoS One 9, 1-20 (2014).

127. Park, S. Y., Kim, G. Y., Bae, S. J., Yoo, Y. H. \& Choi, Y. H. Induction of apoptosis by isothiocyanate sulforaphane in human cervical carcinoma HeLa and hepatocarcinoma HepG2 cells through activation of caspase-3. Oncol. Rep. 18, 181-187 (2007).

128. Zou, X., Qu, Z., Fang, Y., Shi, X. \& Ji, Y. Endoplasmic reticulum stress mediates sulforaphane-induced apoptosis of HepG2 human hepatocellular carcinoma cells. Mol. Med. Rep. 15, 331-338 (2017).

129. Chen, X., Liu, J. \& Chen, S. Y. Sulforaphane protects against ethanol-induced oxidative stress and apoptosis in neural crest cells by the induction of Nrf2-mediated antioxidant response. Br. J. Pharmacol. 169, 437-448 (2013).

130. Baenas, N. et al. Metabolism and antiproliferative effects of sulforaphane and broccoli sprouts in human intestinal (Caco-2) and hepatic (HepG2) cells. Phytochem. Rev. 14, 10351044 (2015).

131. Abdull Razis, A. F. \& Noor, N. M. Sulforaphane is superior to glucoraphanin in modulating carcinogen-metabolising enzymes in Hep G2 cells. Asian Pac. J. Cancer Prev. 14, 4235-8 (2013).

132. Bacon, J. R. et al. Dual Action of Sulforaphane in the Regulation of Thioredoxin Reductase and Thioredoxin in Human HepG2 and Caco-2 Cells. J. Agric. Food Chem. 55, 1170-1176 (2007).

133. Bacon, J. R. et al. Sulforaphane and quercetin modulate PhIP-DNA adduct formation in human HepG2 cells and hepatocytes. Carcinogenesis 24, 1903-1911 (2003). 
134. Li, D. et al. Synergy between sulforaphane and selenium in the up-regulation of thioredoxin reductase and protection against hydrogen peroxide-induced cell death in human hepatocytes. Food Chem. 133, 300-307 (2012).

135. Kimberlin, C. L. \& Winterstein, A. G. Validity and reliability of measurement instruments used in research. Am. J. Heal. Pharm. 65, 2276-2284 (2008).

136. Gump, J. M. et al. Autophagy variation within a cell population determines cell fate through selective degradation of Fap-1. Nat. Cell Biol. 16, 47-54 (2013).

137. Snijder, B. \& Pelkmans, L. Origins of regulated cell-to-cell variability. Nat. Rev. Mol. Cell Biol. 12, 119-125 (2011). 